Portland State University

PDXScholar

7-27-1979

\title{
Die moderne Großstadt in ausgewählten Werken deutscher Lyriker
}

Hildegard Goranson

Portland State University

Follow this and additional works at: https://pdxscholar.library.pdx.edu/open_access_etds

Part of the German Literature Commons, and the Poetry Commons Let us know how access to this document benefits you.

Recommended Citation

Goranson, Hildegard, "Die moderne Großstadt in ausgewählten Werken deutscher Lyriker" (1979). Dissertations and Theses. Paper 2891.

https://doi.org/10.15760/etd.2883

This Thesis is brought to you for free and open access. It has been accepted for inclusion in Dissertations and Theses by an authorized administrator of PDXScholar. Please contact us if we can make this document more accessible: pdxscholar@pdx.edu. 
AN ABSTRACT OF THE THESIS OF Kildegard Goranson for the Master of Arts in German presented July 27. 1979.

Title: Die moderne Großstadt in ausgewählter Werken deutscher Jyriker.

APPROVED BY MEMBERS OF THE THESIS COMMITTEE:

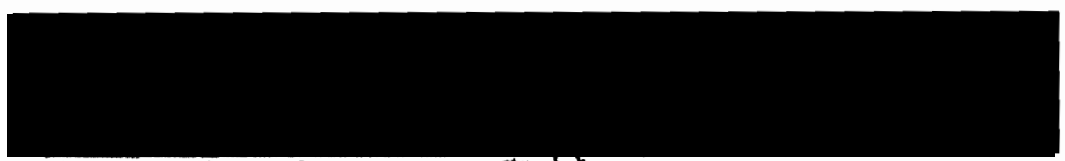

Franz Langhammer, Chalrman

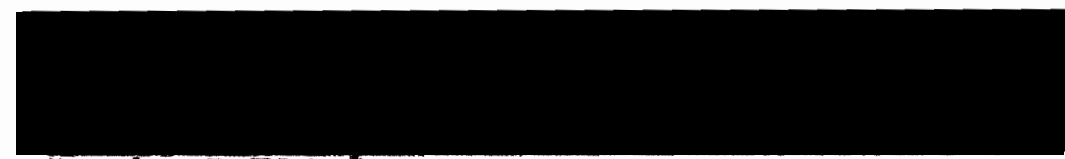

Louis J.EItelto

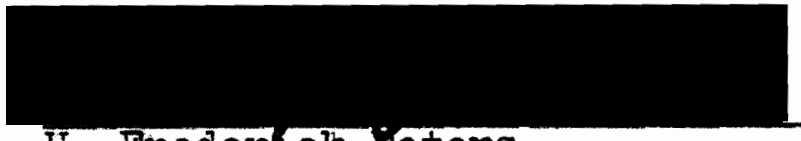

H. Frederlak Yeters

It is the purpose of this thesis to discuss the works of German poets who describe the large modern city: and deal with various aspects of city life and city people. Over the past centuries German poets have written about subjects such as nature, love, heroism and many others, but only in the last hundred years does the city appear as an independent, new theme in German lyric. The thesis briefly reviews the development of Germam cities since the early Middle Ages showing their steady 
growth in area and population that eventually results in the metropolis of our time.

It can be gathered from historical documents as well as from humorous, ironic, or mocking verses and songs that the rural towns of the Middle Ages had to deal with problems like pollution, noise, war, low morals of city dwellers, and others. Similar problems abound in the cities of our times, aggravated by industrialization, mechanization and overpopulation.

A review of the literary movements shows that the city and the various aspects of city life are depicted for the first time in German literature during the epoch of Naturalism. Numerous city poems were written during the expressionistic movement, but in the following years the number declined. During the Third Reich the writing of city literature was not encouraged, but since the end of World War II some German poets have taken up the theme of the large city again.

The main body of the thesis deals with different aspects of the large modern city such as living conditions, pollution, noise, loneliness, and decadence.

It can be discerned that some poets view the city objectively and dispassionately while others exhibit in their works deep emotional involvements. It becomes apparent that the poets represent the attitudes and opinions of their era since they are 'children of their time'. 
An attempt was made to cite a wide variety of city poems written by authors with different backgrounds in order to give an adequate cross section of Germanicity Iyric.

Some poems are complimentary, praising the big city as the center of culture and progress while others describe the large city as evil and degenerated. 
DIE MODERNE GROBSTADT

IN

AUSGEWAHLTEN WERKEN DEUTSCHER IYRIKER

by
HIIDEGARD GORANSON

A thesis submitted in partial fulfillment of the requirements for the degree of

\author{
MASTER OF ARTS \\ in \\ GERMAN
}

Portland State University

1979 
TO THE OFFICE OF GRADUATE STUDIES AND RESEARCH.:

The members of the Committee approve the Thesis of Hildegard Goranson presented July 27, 1979.

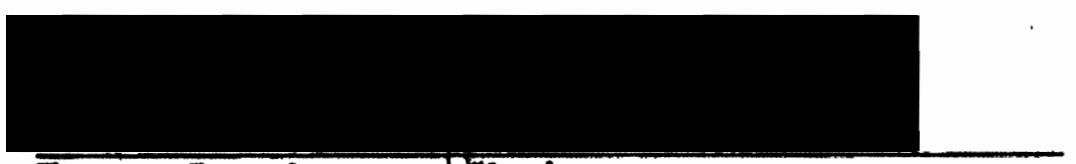

Franz Langhammerlehairman

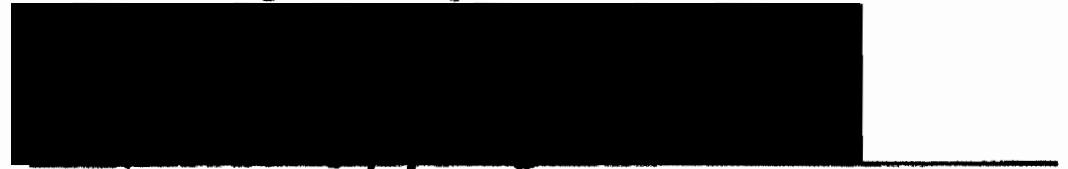

Louis J.Elteto

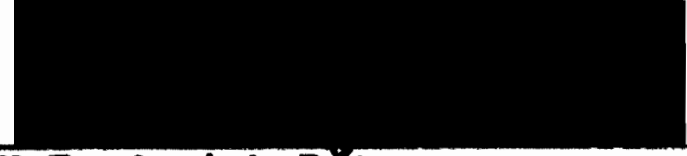

H. Frederick Peters

APPROVED:
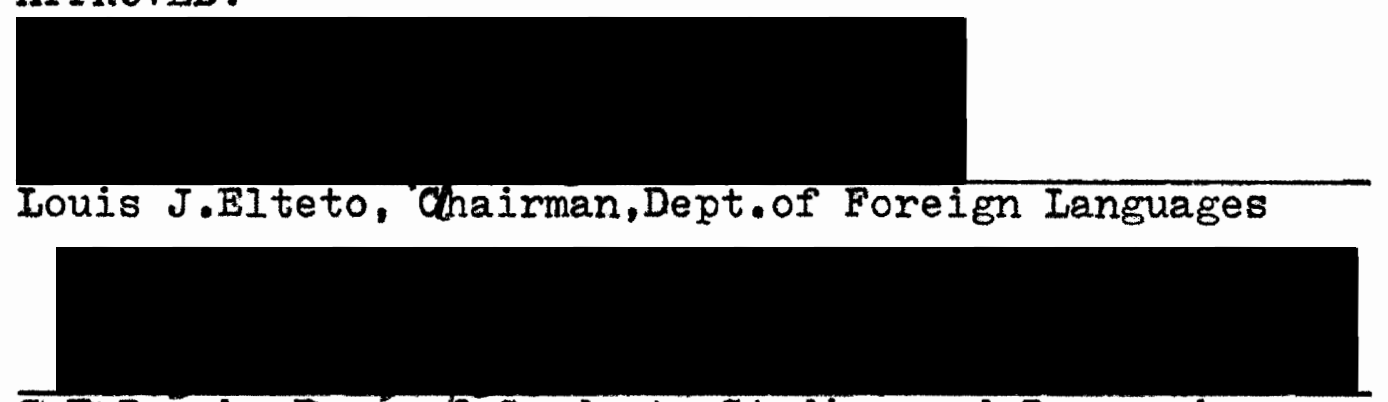

S.E.Rauch, Dean of Graduate Studies and Research 


\section{INHAIT}

KAPITEL

SEITE

I DIE GESCHICHTIICHE ENTWICKIUNG DER STADT

II DAS THEMA »STADTR IN DEUTSCHER IYRIK ... 10

Im Naturalismus . . . . . . . 10

Im Expressionismus . . . . . . 13

Von 1920 bis zur Gegenwart . . . . 15

II ASPEKTE DER GROBSTADT DARGESTELIT AN AUSGEWAHLTEN GEDICHTEN • • . . . . • • 19

Das unaufhaltsame Wachsen der Stadt . . 21

Die Vorstadt . . . . . . . . 26

WohnverhäItnisse ........ 32

Verschmutzung der Städte und

Entfremdung von der Natur . . . . 36

Der Iärm der Großstadt . . . ... . 43

Klassenunterschiede und soziales Elend......... 48

Nachtleben und Dekadenz . . . . . 53

IV . DER MENSCH IN DER GROBSTADT . . . . . . 59

Seine Einsamkeit und Furcht . . . 59

Kinder der Großstadt ........ 64

V GROBSTADT BERLIN . . . . . . . . 67

VI DIE STADT IM KRIEG . . . . . . . . 72 
KAPITEL

VII SATIRE, IRONIE UND HUMOR IN STADTGEDICHTEN . . . . . . . •

VIII DIE IIEBE ZUR STADT . . . . . . . 80

IX MYTHISIERUNG DER STADT . . . . . • 85

$X$ METAPHERN UND FARBEN IN STADTGEDICHTEN $\quad \cdot . \cdot \cdot \cdot \cdot \cdot \cdot \cdot \cdot \cdot$

XI ZUSAMIVENFASSUNG . . . . . . . . . 95

ANIERKUNGEN

BENUTZTE LITERATUR . . . . . . . . . . . 109

VERZEICHNIS DER DICHTER UND GEDICHTE . . . . . . 114 
DIE GESCHICHTLICHE ENTWICKIUNG DER STADT

Ein kurzer Rückblick auf die Entwicklung der deutschen Stadt soll zu dem eigentlichen Thema dieser Arbeit führen, dem Bild der großen stadt in der modernen deutschen Iyrik.

Statistiken, Daten und so manches bedeutsame Ereignis in der Geschichte der Stadt können nur flüchtig gestreift werden.

Es soll hier aber ein Vergleich gezogen werden zwischen den Städten des Mittelalters und der Großstadt von heute, um darauf hinzuweisen, daß sich bereits die kleine Stadt vergangener Jahrhunderte mit ähnlichen, offensichtlich den Städten inhärenten Problemen zu befassen hatte wie die große Stadt der Gegenwart.

Obwohl in der deutschen Lyrik des siebzehnten, achtzehnten, und der ersten Hälfte des neunzehnten Jahrhunderts ein gelegentliches Stadtgedicht $z u$ finden ist, kann erst seit Ende des letzten Jahrhunderts von einer wirklichen "Stadtlyrik» gesprochen werden. 
Als Hauptepoche der deutschen Städtegründung werden das neunte und zehnte Jahrhundert angegeben, und es wird geschätzt, daß im Jahre 1000 ungefähr neunzig stadtähnliche, befestigte Siedlungen im deutschen Sprachraum bestanden. Obwohl diese Zahl im vierzehnten Jahrhundert bereits auf 4000 angestiegen war, hatten die meisten Städte dieser Zeit noch einen sehr dörflichen Charakter.

Das Bild der mittelalterlichen Stadt wurde von wilhelm Grimm Anfang des neunzehnten Jahrhunderts beschrieben:

Was kann reizender sein als das Bild einer Stadt des Mittelalters? Künste, die nur Reichtum ernährt, zogen herbei, kunstreiche Kirchen und öffentIiche Gebäude stiegen auf in den sichernden Mauern, grün bepflanzte Plätze erheiterten die zutraulichen Wohnungen, und darinnen ein arbeitsames, reges Schaffen neben aller lust im Spiel, Scherz, Tanz und Kriegsübungen. Eines gegründeten Reichtums sich bewußt, gingen die schön gekleideten Bürger daher, stolz auf ihre Freiheit, tapfer sie verteidigend gegen jede Anmaßung, großmütig in Geschenken, ehrbar und streng in ihrer Familie und fromm vor Gott.1

Wie man aus Chroniken des Mittelalters schließen kann, war Wilhelm Grimms Darstellung sicherlich etwas zu romantisch. Auch die mittelalterliche stadt hatte mit mancherlei Problemen zu tun wie Schmutz und Verunreinigung, Verwüstung durch Krieg und Raubüberfälle, Sittenlosigkeit der Bürger und soziale Mißstände.

Aus alten Urkunden geht hervor, daß selbst in den größeren Handelsstädten von den Bürgern Schweine, Kühe und Schafherden gehalten wurden, nicht zu vergessen Tauben, 
Gänse und anderes Federvieh. Es wurde als eine 'Entartung' betrachtet, wenn der Bürgersmann 'nit dafür sorge, das er eigen Hausvieh habe, und alles Fleisch und die Milch kauffen müße'. In mehreren großen städten mußte der stadtrat ein Verbot erlassen, Schweineställe an der Straßenseite der Häuser anzubringen. So wurde zum Beispiel in Nürnberg im Jahre 1475 das freie Umherlaufen der Schweine in den Straßen untersagt, und der Regensburger Stadtrat mahnte die Bürger vor einer Leichnamsprozession im Jahre 1452:》 . . daß jedermann den Mist in der Stadt ausführe, und wer Kot habe, unverzüglich strohen und nach acht Tagen den Mist wegschaffen soll. ${ }^{2}$

Der Vers eines unbekannten Dichters aus Nürnberg gibt einen Einblick in die hygienischen Zustände dieser, und sicher so mancher anderen Stadt gegen Ende des fünfiehnten Jahrhunderts :

Ein yeglich peck und pfragner mus in seinem haus bey eides trew nit haben mer denn zehen sew. Wer auf die mast legt mer enpor, der mus sy haben vor dem thor, auf das er die bus behelt. Auch ist ein knecht dazu bestelt, der alle tag mit der butten geht, ob yemand hingeworfen het todte sew, hund oder katzen, schelmig hüner oder ratzen: wa er die findt, er nymts enpor, tregtz in der butten vor das thor dadurch die gasz gesewbert würt. 3

Man mag sich eines Lächelns nicht erwehren können, wenn man diese Probleme der mittelalterlichen Stadt- 
verunreinigung liest. Wie die Stadtgedichte unserer Zeit jedoch zeigen, haben sich moderne Großstädte ebenfalls mit dem Mißstand der Verschmutzung zu befassen--auch wenn der Kulprit nicht Schweine sind--ohne daß jedoch eine Iösung dafür in Aussicht steht.

Wie friedlos die Zeiten des Mittelalters waren, geht aus so mancher alten Urkunde hervor. Nicht nur Städte lagen miteinander in Fehde, auch Raubritter machten den wohlhabenden städtischen Kaufleuten viel zu schaffen. Eine solche Begebenheit ist in einem Gedicht aus dem Jahre 1439 beschrieben. Die Bürger der Stadt Rothenburg zogen mit hundertfünfzig Wagen aus, um sich an dem Raubritter Wilhelm von Elm zu rächen, der ein paar Kaufleute ihrer Stadt gefangen hielt und den sie dann kurzerhand enthaupten ließen:

An einem sonntag es geschach, daß man das banner außziehen sach zu Rotenburg auß der mauern: sie zugen über die landwer hinauß, die bürger und die bauern. 4

Zweihundert Jahre später ging der Dreißigjährige Krieg über das Land, in dem so manche deutsche Stadt bis zu einem Drittel ihrer Einwohnerzahl verlor. Viele der damals etwa fünfig großen Städte schrumpften zu Kleinstädten zusammen und büßten ihre wirtschaftliche Bedeutung ein, die sie auch im Laufe vieler Jahrzehnte nicht mehr zurückgewinnen konnten. Andreas Gryphius, der oft 'der Dichter des Dreißigjährigen Krieges' genannt wird, beschreibt in "Untergang der Stadt Freystadt« die Verwüstung dieser Stadt، 
Dort fällt ein Hauß zusammen

Und schlägt das ander' ein.

Was nicht von diesem schmaucht

Ist schon Staub, Asch' und Grauß:

Wo jener Hauffen raucht

War vor der schönste Saal:

Wo sind der Thürme Spitzen?

Wo ist das Rathhauß hin?5

Dreihundert Jahre nach der Entstehung dieser Verse befaßte sich die deutsche Stadtlyrik mit demselben Thema, mit der Zerstörung der Städte im Krieg, nur daß es sich jetzt um die Folgen des Zweiten Weltkriegs handelte.

Es ist hinreichend dokumentiert, daß die Bürger der mittelalterlichen Städte auch gern ihren Vergnügungen nachgingen und ihre Sünden und Laster hatten. Johannes Janssen berichtet in Culturzustände des Deutschen Volkes von den städtischen Badestuben, die sich großer Beliebtheit erfreuten und 'zur Reinigkeit und Beheglichkeit der Gesellen und anderer dienenden und armen Leut in Stedten und Dörffern hergerichtet sindt.' Ein Augenzeuge aus dem fünfzehnten Jahrhundert war jedoch anderer Meinung:

Und sind auch für die Gesellen Badestüblein im Hause besser dan die sunstigen Badeorte zum gemeinen gebrauch, weil hie nit selten manch unfug geschiet. In den badestuben wird manch schendichkeit getriben als auch in den wirtshüsern. 6

Auch der Kleideraufwand der Bürger hatte im Mittelalter unglaubliche Ausmaße angenommen. Ein Vers, der sich auf die Eitelkeit und Prunksucht der Stadtrauen bezieht, 
wirft ihnen vor, daß sie es den Fürsten- und Ritterfrauen in der Kleidung gleichtun wollen:

Die Weiber sind mit veh beschnitten,

Gezieret wol nach edlen sitten,

Wer kann sie unterscheiden?

Es stund viel bass vor alter zeit,

$\mathrm{Da}$ füchsen war ihr bestes kleid.?

Wie es mit der Moral der Bürger Anfang des sechzehnten Jahrhunderts bestellt war, geht aus einem Gedicht von Hans Sachs hervor. Er beschwert sich über die 'freventliche Entheiligung des Sonntags durch Arbeiten, Fechten, Jagen, Völlerei, Hader, Todschlag, Unzucht und Ehebruch' und fährt fortı
Ganz unverschämt und unverhol, daß schier stecken alle Gassen voll Thaiber und unehrlicher Weiber, Jungfrau-Schwächer und Eärentreiber, Ehbrecher und Ehbrecherin Und Leut, die sunst unehlich sin. Gemeiner denn bei Juden und Heiden So unzüchtig und unbescheiden, da $\beta$ sich niemand schämet mehr. 8

Ein unbekannter Bauerndichter bestätigt die Beobachtungen Hans Sachs':

Iluchen, schwören, tapfer liegen, mit Gewicht und Maß betriegen, nit minder spielen umb groß Geld, und Pfaffen schimpfen für und für im Wirtshuß stracks bei Wein und Bier. 9

Wenn die Untugenden der Stadtbewohner nun auch andere Formen angenommen haben--die Menschen bleiben sich doch immer gleich. 
Die anklagenden Worte Hans Sachs' und des einfachen Bauerndichters finden einen unverkennbaren Widerhall in den Stadtgedichten unseres Jahrhunderts. Auch in der modernen Iyrik wird die Vergnügungssucht, Sündhaftigkeit und Dekadenz des Großstadtmenschen dargestellt.

Naturgemäß treten Klassen- und Standesunterschiede besonders drastisch in der Stadt in Erscheinung. Dies ist auch bereits für die frühen deutschen städte zutreffend. Den Patriziern allein waren Ratsfähigkeit und alle wichtigen Stadtämter vorbehalten, was schon im dreizehnten Jahrhundert als Ungerechtigkeit empfunden wurde und zu den ersten Erhebungen der zünfte gegen die Patrizier führte.

Viele Spottverse dieser Zeit richten sich gegen die Bestechlichkeit der Richter und Juristen. Wenn es um Schuldfragen ging, waren die weniger Bemittelten fast immer im Nachteil, während die bestechlichen Rechtssprecher sich auf die Seite der Reichen stellten:

Es ist ein volk zu teutsch juristen, wie seyndt mir das so seltsam Christen! Sie thunt das recht so spitzig biegen und können's, wo man wili, hinfügen.10

Ahnliche Probleme kommen auch in der modernen Stadtdichtung zum Ausdruck, wo die krassen Standesunterschiede und soziale Ungerechtigkeit angeprangert werden.

Sicher ließe sich noch manch andere Parallele zwischen den frühen Städten und der modernen Großstadt ziehen. Jedoch zeigen die bisherigen Ausführungen deutlich genug, daß 
gewisse Aspekte der Stadt und des Stadtlebens zeitlos und universal sind.

Im achtzehnten und neunzehnten Jahrhundert stieg die Einwohnerzahl der deutschen Städte beträchtlich an. Um 1850 wohnte bereits jeder Dritte in einer stadt, und Berlin hatte als erste Stadt Deutschlands die Einwohnerzahl von einer halben Million erreicht.

Bei der Entwicklung zur modernen GroB-,. Industrieoder Fabrikstadt spielten Industrialisierung, Mechanisierung. und der Ausbau des Verkehrsnetzes in und zwischen den Städten eine bedeutende Rolle. Ebenfalls trug die Modernisierung der Verkehrsmittel zur Veränderung des Stadtbildes bei.

In den Städten des Mittelalters waren Zug- und Reittiere das Haupttransportmittel. In einem Bericht aus jener Zeit ist zu lesen, daß Pferde und Wagen oft im grundlosen Straßenkot zu versinken drohten und die Ratsherren in Holzschuhen oder manchmal sogar auf Stelzen zur Sitzung im Rathaus gehen mußten. In Leipzig waren die Verkehrsstockungen um 1660 an Markttagen so groß, daß schließlich vom Stadtrat 'Alle karreten in der stadt' verboten wurden.10 Mitte des neunzehnten Jahrhunderts wurden die Stadtbewohner von Pferdedroschken und -omnibussen befördert. 1881 wurde die erste Stadtbahn in Betrieb gesetzt und damit die Technisierung des gesamten Stadtverkehrs eingeleitet.

Etwa zur selben Zeit vollzog sich eine Anderung des ganzen Stadtbildes: Gewerbe und Industrien zogen vom Zentrum 
zu den Außenbezirken der Stadt, während sich Geschäfte, Verwaltungsgebäude, kulturelle Bauten und Gast- und Vergnügungsstätten in der Stadtmitte ausbreiteten. Obwohl MilIionen Menschen hauptsächlich der Verdienstmöglichkeiten wegen in die Städte zogen, ist nicht zu übersehen, daß die Großstadt als Zentrum der Kultur und des Vergnügens eine starke Anziehungskraft ausübte.

Während es um 1870 nur drei deutsche Großstädte gab mit einer Einwohnerzahl über 250 000--Berlin, Hamburg, München--war diese Zahl siebzig Jahre später bereits auf zweiundvierzig angestiegen.

Sō unerläBlich nüchterne Zahlen und Statistiken auch sein mögen, sie enthüllen nichts über die Menschen in den Städten, über ihre Freuden und Nöte, ihr Tun und Treiben, über die Iicht- und Schattenseiten des Großstadtlebens.

Es scheint den Dichtern und Schriftstellern vorbehalten, das Wesen der Stadt und ihrer Menschen zu ergründen und $z u$ erfassen und in Romanen und Dramen, Novellen und Geschichten, und nicht zuletzt in der Lyrik darzustellen. 
DAS THEMA »STADT* IN DEUTSCHER IYRIK

ObwohI die Stadt schon seit dem Mittelalter besondere Bedeutung hatte als Mittelpunkt des wirtschaftichen und kulturellen Lebens, erscheint sie in der deutschen Lyrik als selbständiges Thema verhäItnismäßig spät.

Wohl schildert Andreas Gryphius bereits im siebzehnten Jahrhundert die Not und Verwüstung so mancher deutschen Stadt in seinen Gedichten, doch ist nicht die Stadt als solche das eigentliche Hauptthema seiner Werke, sondern vielmehr die Sündhaftigkeit und Vergänglichkeit des Menschen.

Die Stadtgedichte der folgenden Jahrhunderte befassen sich fast ausschließlich mit dem romantisch gelegenen städtchen, dem geliebten Heimatort, oder der ehrwürdigen alten Universitätsstadt. Es geht den Dichtern aber nicht darum, die Stadt als solche darzustellen, sondern sie dient nur als beiläufiges Thema zum Ausdruck ihrer Gefühle.

Erst seit Ende des neunzehnten Jahrhunderts kann von einer wirklichen Stadtlyrik gesprochen werden, als die stadt als selbständiges Thema in der deutschen Dichtung auftrat.

Im Naturalismus

In Über die großen Städte gibt Fritz Hofmann der 
Meinung Ausdruck, daß es der Verdienst der Schriftsteller und Lyriker des Naturalismus war, die Großstadt als 'Gegenstand dichterischer Gestaltung' entdeckt zu haben. ${ }^{1}$ Doch muß erwähnt werden, daß die deutschen Iyriker von Dichtern anderer Iänder angeregt wurden, die sich schon vor ihnen mit dem Thema der stadt befaßt hatten.

In diesem Zusammenhang sollen die französischen Iyriker Arthur Rimbaud, Charles Baudelaire, Jules Laforgue und Emile Verhaeren genannt werden, deren Werke nachweisbar einen großen Einfluß auf mehrere deutsche Dichter ausübten. 2

Die frühen deutschen Stadtgedichte des Naturalismus zeigen oft eine positive Einstellung zur Stadt. Arno Holz schrieb:

Nein, mitten nur im Volksgewüh Beim Ausblick auf die großen Städte, Beim Klang der Telegraphendrähte, Ergießt ins Wort sich mein Gefühl. 3

Doch schon bald überwiegt der Realismus, und die große Stadt wird 'naturgetreu' in ihrer grauen Eintönigkeit und mit ihren sozialen Problemen dargestellt--als ein 'Ungeheuer', wie sich Karl Henckell ausdrückte.

In Die Stadt bei Stadler, Heym und Trakl schreibt Heinz Rölleke,daß sich die Stadtdichter des Naturalismus eigentlich nur mit einem Aspekt der großen Stadt befaßten, nämlich mit den sozialen Zuständen. 
Rölleke sagt weiterhinı

Der Wille zum Sozial- und zum Großstadtgedicht war geweckt, aber es blieb eben doch meistens nur ein Schritt ins Ieben, und auch die Stadtlyrik der nächsten fünfundzwanzig Jahre kam kaum darüber hinaus. Erst als Dichter es wagten, die Heillosigkeit nicht nur der sozialen Zustände, sondern der ganzen Stadtwelt zu gestalten, ist eine allumfassende Stadtlyrik entstanden. Das im Naturalismus entdeckte Motiv wurde im Expressionismus zu einem Mittelpunkt. 4

Am Ende der naturalistischen Iiteraturströmung um die Jahrhundertwende machten sich für kurze Zeit die neoklassische, neuromantische, und eine als "Heimatkunst« bezeichnete Richtung bemerkbar, die jedoch die Stadt als lyrisches Thema vollkommen ablehnten. Hermann Iöns, der der Heimatkunst-Strömung angehörte, bezeichnete die Stadtlyrik als 'Asphaltkultur'.

In Modern German Iiterature 1880-1950 äußert sich Jethro Bithell über den Utbergang vom Naturalismus zum Expressionismus in der Iyrik und vertritt eine Ansicht, der sich auch andere Iiteraturkritiker anschließen.

There is no essential discontinuity between the lyric poetry of the naturalistic and expressionistic periods and that of the preceding period. The themes of poetry are essentially the same they:are merely different in atmosphere and interpretation. Certain of the old themes are fitted into new times. The poetry of the town takes on the form of Großstadtpoesie', the city becomes 'die megäre Stadt'.5 


\section{Im Expressionismus}

In der Iyrik des Expressionismus, etwa 1910 bis 1925. spiegeln sich faszinierende, oft zwiespältige Eindrücke über die große Stadt wider. Wie Karl Ludwig Schneider sagte, wandten sich die Lyriker dieser Epoche gegen $\gg d e n$ sterilen Asthezismus und Schönheitskult der Neuromantik und nahmen an der neuen dynamischen Lebensgewalt teil. «6

Allerdings hatte die große Stadt nicht für alle Dichter die gleiche Bedeutung. Während manche Iyriker des Expressionismus von ihren Reizen, von der Vielfältigkeit des Stadtlebens inspiriert und angezogen wurden, sahen wieder andere die negativen Seiten der Großstadt und drückten in ihren Gedichten Enttäuschung, Abscheu, ja sogar Furcht aus.

Silvio Vietta bemerkt in Lyrik des Expressionismus, da $B$ die jungen Dichter die Umschichtung von der kleinstädtischen Gemeinschaft zur unpersönlichen Gesellschaft beobachteten und selbst von ungeheuren Spannungen erfüllt waren. Diese waren auf das dissonante Leben in der großen Stadt zurückzuführen und fanden ihren Niederschlag in der Stadtlyrik des Expressionismus.?

Die Dichter dieser Zeit sehen die Stadt mit kritischen Augen und befassen sich mit zahlreichen Aspekten des Stadtlebens und der Menschen, die in den großen Städten wohnen. Auch weist inre Lyrik neue Sprach- und Ausdrucks- 
formen auf, die charakteristisch für die expressionistische Iiteraturströmung sind.

Die Reichshauptstadt Berlin war der Ausgangs - und Mittelpunkt der Großstadtlyrik des Expressionismus. Es waren vor allem die jungen Dichter des Neuen Clubs, die das 'Phänomen Stadt' auf neuartige. Weise darstellten. Kurt Hiller, Mitbegründer dieses Iiterarischen Glubs, setzte sich intensiv für Stadtdichtung ein.8 Er prophezeite in seinem Essay "Die Weisheit der Langeweile*, daß von 'Waldesgrün und Lerchensang, von Herz und Schmerz und Lust und Brust, von Sinnigkeit und Innigkeit bald nichts mehr in der deutschen Lyrik übrig sein werde, denn:

Das Paradies ist kein Garten Eden; es sieht eher aus wie eine schöne, ganz große Stadt. Das Paradies ist nicht arkadisch, vielmehr zeigt es die fabelhafte Zivilisation, mit Industrie, Technik, Schule, Verkehr--allem.9

Es wird oft behauptet, zu recht oder unrecht, daB den Dichtern des Expressionismus die Stadt 'in Fleisch und Blut' übergegangen ist. Besonders hatte es ihnen die Stadt Berlin angetan, die das Thema zahlreicher Gedichte wurde. Zwar wurden später auch andere große Städte dargestellt wie Hamburg, Köln, Düsseldorf, Dresden, Stuttgart, aber Berlin hat nie seine Faszination für die deutschen Lyriker verloren.

Das Ende der expressionistischen Literaturströmung machte sich bald nach 1920 bemerkbar, und in den folgenden 
Jahrzehnten bis zur Gegenwart kann von keinen einheitlichen, deutlich definierbaren Iiteraturrichtungen mehr gesprochen werden.

\section{Von 1920 bis zur Gegenwart}

Obwohl das Thema "Stadt* auch weiterhin aktuell blieb, ist die Zahl der zwischen 1920 und 1933 entstandenen Stadtgedichte zurückgegangen.

Anfang der zwanziger Jahre wurde die Stadt von politisch interessierten und aktiven Dichtern als Ausgangspunkt für den sozialen und politischen Umsturz angesehen. Manche Iyriker befaßten sich mit den technischen Aspekten der Stadt und schrieben über neue Verkehrsmittel, Reklame, oder moderne Riesenbauwerke. Auch die neuerwachte Lebens- und Vergnügungssucht der Stadtmenschen, die sich nach Ende des Ersten Weltkrieges bemerkbar machten, kamen in der Stadtlyrik dieser Jahre zum Ausdruck.

Alfred Döblin, der Autor des Stadtromans Berlin Alexanderplatz, machte folgende Beobachtungen, die auch für die Stadtlyrik dieser Zeit Gültigkeit haben:

Zum Erlebnisbild der heutigen Menschen gehören Straßen, die sekündlich wechselnden Szenen auf der Straße, die Firmenschilder, der Wagenverkehr. - $\because$ Jetzt ist ein Ilann nicht größer als die Welle, die ihn trägt. In das Bild von heute gehört die Zusammenhanglosigkeit seines Tuns, des Daseins überhaupt, das Flatternde, Rastlose.10 
Wie in den vorhergehenden Jahrzehnten, ist in den Gedichten dieser Jahre auch von der Einsamkeit des Stadtmenschen die Rede, der vom Wirbel der schnellebigen stadt mitgerissen wird, seinen Halt verliert und in der Masse untergeht.

Während des Dritten Reiches war jegliche Form von Stadtiteratur als verfemte 'Asphalt- oder Rinnsteinliteratur' verboten. Viele deutsche Lyriker, die in diesen Jahren das Land freiwillig oder gezwungen verließen, schilderten ihre Erfahrungen und Eindrücke in den fremden Städten des Auslands, soda $B$ von einer Art NmigrantenStadtlyrik gesprochen werden könnte. Es gibt Gedichte über die Städte Zürich, Paris, London, Mailand, Moskau, New York, um nur einige zu nennen.

Auch in der Lyrik der letzten drei Jahrzehnte hat das Stadtgedicht wieder einen Platz gefunden. Allerdings muB seit 1949 zwischen der Lyrik der Deutschen Demokratischen Republik und der Bundesrepublik unterschieden werden. Beide Iänder vertreten verschiedene Weltanschauungen, die nicht zuletzt in der Stadtlyrik zum Ausdruck kommen.

In der Dichtung der DDR werden fast ausschlieBlich die positiven Aspekte der Stadt hervorgehoben: Wiederaufbau und Verschönerung der zerstörten Städte, Zufriedenheit und Stolz der Stadtbewohner.

Wie aus Günter Kunerts Gedicht. "Es sind die Städte» hervorgeht, wird der Stadt große politische Bedeutung 
zugemessen:
Die Stadt ist die Erste.
Die Stadt fängt an.
Die stadt beginnt.
Die stadt ist der stein.
$\dot{\mathrm{D}} \dot{\mathrm{e}} \dot{\mathrm{S}} \dot{\mathrm{a}} \mathrm{d} t \mathrm{beginnt.}$
Die stadt ist der Mund.
Die Stadt ist Faust und
Banner roter Farbe.11

Fritz Hofmann, ein Iiteraturkritiker aus der DDR, gibt eine bezeichnende Beschreibung der Stadtlyrik seines Landes:

Daseinsfreude beginnt sich zu regen, die Stadt gewinnt ihre Farbe zurück. Dichtung und stadt sind eine neue Gemeinsamkeit eingegangen, beide jung und von hohem Anspruch erfüllt. Eine Lyrik entsteht, die verhaltener, sensibler geworden ist, die von einem Stadterlebnis ausgeht, das klare Iinien, überschaubare Verhältnisse vorfindet, das den Rhythmus der riesigen Bauplätze, der Werkhallen, des Alltags der arbeitenden Menschen in sich trägt.12

Das Thema "Stadt" gehörte in den letzten Jahrzehnten nicht $\mathrm{zu}$ den vorherrschenden Themen in der westdeutschen Iyrik. Es gibt aber doch eine Anzahl Gedichte, die sich mit zeitgemäßen Problemen der Stadt und des Großstadtmenschen befassen. Diese Gedichte unterscheiden sich grundlegend von denen der Deutschen Demokratischen Republik, was sicher zum Teil mit der Freiheit der Meinungsäußerung zusammenhängt.

Es mag als Zeichen der Zeit gelten, daß viele moderne 
Stadtgedichte des Westens oft pessimistisch sind. Die alten Probleme der Stadt und ihrer Menschen--Verschmutzung, Wohnungsnot, Vereinsamung, und andere--sind in verstärktem Maße vorzufinden, und es besteht wenig Aussicht auf eine Iösung. 


\section{III}

\section{ASPEKTE DER GROBSTADT \\ DARGESTELIT AN AUSGEWAHLTEN GEDICHTEN}

Wenn man auch nur einen kleinen Teil der zahlreichen Stadtgedichte der letzten hundert Jahre liest, bemerkt man, da $B$ bestimmte Aspekte der Stadt und des Stadtlebens besonders häufig in Erscheinung treten.

Es wird hier der Versuch gemacht, diese Aspekte herauszukristallisieren und Gruppen von Gedichten zusammenzustellen, die sich jeweils mit einem bestimmten Aspekt befassen. MancheAspekte der Stadt sind zeitlos und universell. Sie erschienen bereits in den ersten Stadtgedichten vor der Jahrhundertwende und sind auch in der Lyrik der Gegenwart zu finden. Es gibt aber auch einige Aspekte, die nur während einer begrenzten Zeitepoche aktuell waren und in der Dichtung Ausdruck fanden. Dazu gehören unter anderem "Die Stadt im Krieg« und $\gg$ Die mythisierte Stadtr.

Die Reihenfolge, in der die einzelnen Gedichtgruppen besprochen werden, ist nach bestimmten fberlegungen festgesetzt. Zuerst werden solche Gedichte erwähnt, die sich mit dem konkreten physischen Bild der. Stadt befassen, mit der Vorstadt, den Wohn- und Fabrikvierteln und ähnlichem. Danach folgen Gefichtgruppen, die den Stadtmenschen, 
seine Arbeit, seine Lebensverhältnisse und Gefühle schildern. Verschiedene Einzelmotive wie "Großstadt Berlink, "Die Stadt im Krieg» und andere bilden den Schluß.

Es soll an dieser Stelle erwähnt werden, dall es selbstverständlich auch Stadtgedichte gibt, die.sich in keine der hier angeführten Gruppen einordnen lassen. Dazu gehören unter anderem Gedichte, die sich mit den Bauwerken, Verkehrsmitteln und ähnlichen Aspekten der Stadt befassen. Es muß jedoch davon abgesehen werden, auf solche Gedichte einzugehen.

Nur eine kleine Anzahl repräsentativer stadtgedichte kann in dieser Arbeit zitiert werden. Dabei wird angestrebt, die Werke von Lyrikern verschiedener Generationen und verschiedener Iiteraturrichtungen zur Sprache kommen zu lassen. SchlieBlich ist es nur auf diese Weise möglich, die mannigfaltigen Aspekte der Stadt und des Stadtlebens von mehreren Seiten zu beleuchten und $\mathrm{zu}$ veranschaulichen.

Einige der bekanntesten Stadtgedichte werden in dieser Arbeit nicht besprochen, da sie bereits von mehreren Literaturkritikern eingehend diskutiert und definiert worden sind. Andererseits sind aber verschiedene Gedichte von bisher noch fast unbekannten Dichtern zitiert: Die Auswahl der hier angeführten Werke soll also keineswegs ein Werturteil darstellen, sondern erfolgt lediglich nach den oben erwähnten Gesichtspunkten. 
DAS UNAUFHAITSAME WACHSEN DER STADT

Schon im siebzehnten Jahrhundert wurde die Einwohnerzahl der meisten großen deutschen Städte: statistisch erfaßt. Es ist daher möglich, das Wachsen der Städte über fast vier Jahrhunderte hindurch zu verfolgen.

Die Industrialisierung Deutschlands brachte die 'Flucht vom Lande' in der zweiten Hälfte des neunzehnten Jahrhunderts mit sich, und Statistiken verzeichnen ein ungewöhnlich rasches Anwachsen der Bevölkerung der großen Industriestädte. Die Folge davon waren Wohnungsnot, der Bau von Mietskasernen, und die räumliche Ausbreitung der stadt auf Kosten umliegender landwirtschaftlicher Gemarkungen.

Armin Wegner, ein Dichter des Frühexpressionismus, beobachtete diese Entwicklung und gab den Befürchtungen Ausdruck, daß immer mehr offenes Ackerland der Stadt zum Opfer falle.l

In »Der Zug der Häuser» personifiziert der Dichter die Stadt und läBt das Häusermeer in drohendem Chorus sagen:

Wir wälzen den plumpen steinernen Leib darüber, die Dörfer, die Felder, die Wälder, wir nehmen sie mit: Mit unserem rauchenden Atem verbrennen

wir jede Blüte und reifende Frucht. Die Saaten, die nicht mehr grünen können, ersticken in Qualm wir. Vor unserer Wucht zersplittern die Bäume, in rasender Schnelle sind alle Menschen im Land auf der Flucht vor unserer steinernen Welle. Wir aber erreichen sie doch. 2 
Auch für Rainer Naria Rilke, dessen Stadtgedichte sich hauptsächlich mit dem Elend der Menschen befassen, war die Großstadt etwas unheimlich Lebendiges, das seine Fangarme nach allen Seiten ausstreckt und vor dem es kein Entrinnen gibt. In Das Stundenbuch beschreibt Rilke eine Stadt, die sich das umliegende Land untertan macht:

Das ist dort, wo die letzten Hütten sind und neue Häuser, die mit engen Brüsten sich drängen aus den bangen Baugerüsten und wissen wollen, wo das Feld beginnt. 3

Etwa dreißig Jahre später schildert Karl Krolow das Wachsen einer modernen Großstadt in "Entstehung einer Stadt*. Der Dichter ahnt bereits zukünftige Probleme voraus wie gedrängte Wohnverhältnisse und Straßenlärm:

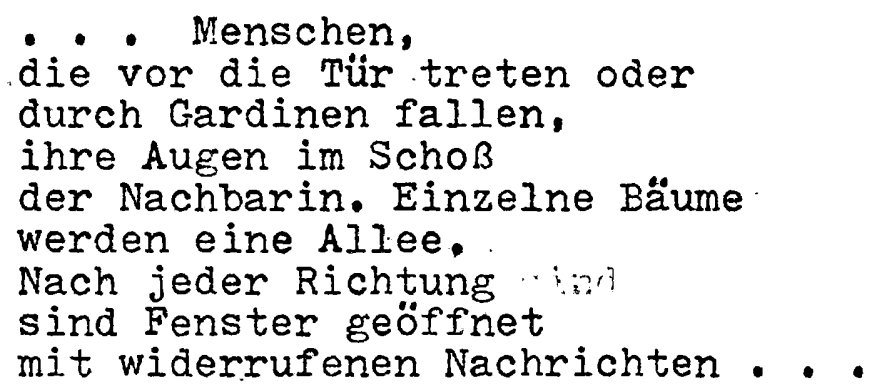

Das Gedicht endet mit der lakonischen Feststellung:

So geht das gesellig weiter. Das Wachstum ist nicht mehr aufzuhalten. 4

Ruth Hallard kontrastiert den alten Backsteinbau einer kleinen Kirche mit den hohen, anmaßenden Neubauten moderner 
Geschäftshäuser, um das Wachsen der Großstadt darzustellen. In ihrem Gedicht "Kircher rührt sie dabei gleichzeitig an ein anderes Problem; das die Menschen der großen Städte betrifft:

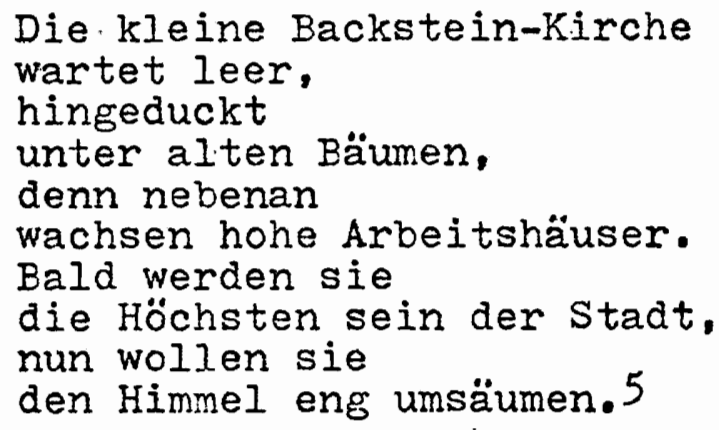

Thilo Koch gibt in "Die gegenwärtige Stadt* eine Beschreibung, wie Vorstädte mit den umliegenden Orten zusammenwachsen und schließlich ein endlos fortlaufendes Häusermeer bilden, wie es in den Industriestädten des Ruhrgebiets $z u$ finden ist:

Nicht schön, nicht leuchtend und einladend nicht, unvereinbar schon immer City und Vorstädte, unübersichtlich das Ausmaß, 40 Kilometer Stadtbahngleis ...6

Im Gegensatz zu diesen Gedichten, die Bedauern und Besorgnis über das ständige Wachsen der Städte ausdrücken, über den Verlust an Grünflächen und Ackerland, findet man in der Stadtlyrik der Deutschen Demokratischen Republik eine andere Einstellung zu diesem Thema.

Das Wachsen der Stadt, der Bau neuer Fabrik- und Wohnviertel wird als etwas Positives angesehen, als ein 
Zeichen des Fortschritts und Aufbaus. Wenn man die Bevölkerungsdichte der DDR mit der der Bundesrepublik Deutschland vergleicht, wird es verständich, warum der Verlust an Grünflächen keine tragische Rolle spielt.?

Die drei folgenden Gedichte junger Iyriker der DDR zeigen die typische idealisierte Auffassung vom Wachsen der Städte. UIIrich Schmidts Gedicht "Unterwegs erschien im Jahre 1969, und der Titel hat offensichtlich eine symbolische Bedeutung:

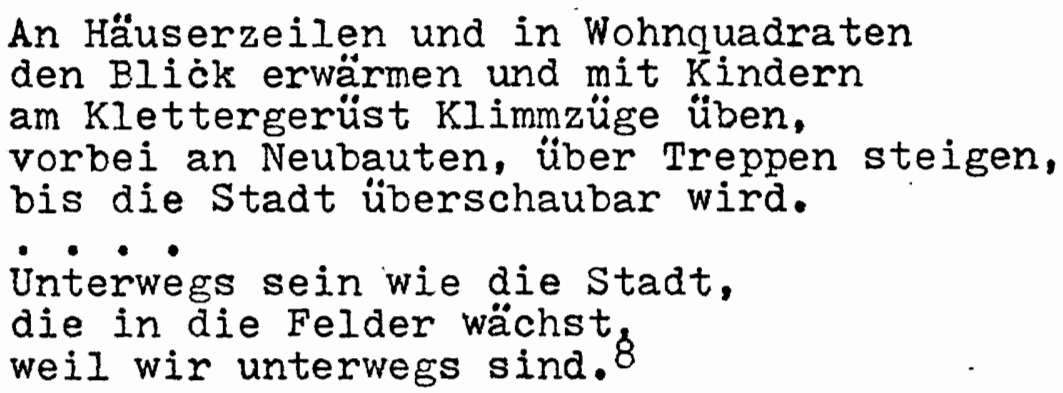

In »Der Rote Turm in Halle« drückt Peter Arlt seinen Stolz über das Wachsen seiner Heimatstadt Halle an der Saale aus und läßt den 'Roten Turm' als Symbol des Aufbaus und einer besseren Zukunft gelten:

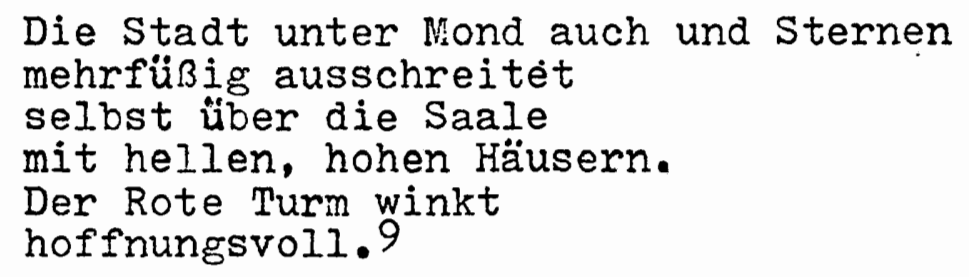

Auch Gerd W. Heyses Gedicht »Stadtbild II《 hat die üblichen politischen Untertöne der DDR-Dichtung. Nur die 
Stadt, die von der Demokratischen Republik gebaut wurde, ist in jeder Hinsicht gut, während alles andere veraltet ist und nichts mehr taugt:

da draußen steht sie

die stadt unsere stadt unsere neue stadt

ablösung vor:

die alte war uns zu alt das mittelalter in ehren doch wir sind junglo 


\section{DIE VORSTADT}

Die Entstehung von Vorstädten wird oft fälschlicherweise als Nebenerscheinung bei der Entwicklung der großen Industriestädte vermutet. Jedoch hatten bereits die mittelalterlichen Städte ihre 'Vorstadt-Siedlungen', die meistens aus einfachen Holzhütten bestanden.

Karl Czok erwähnt in Die Stadt, daB viele mittelalterliche Stiche und Zeichnungen solche Vorstadtsiedlungen erkennen lassen, die ungeschützt vor den Mauern lagen und im Kriegsfall als erste zerstört wurden. Er fährt fort:

Untersuchungen über die Vorstädte von Heidelberg und Dresden haben erwiesen, daß sich dort die vermögensschwachen oder völlig besitzlosen Menschen ansiedelten. Auch ist nachgewiesen, daß im 16. Jahrhundert der größte Teil der Leipziger Handwerksmeister vor den Toren der Stadt wohnte.11

Die Vorstadt, die also schon vor Jahrhunderten ebenso wie heute den Minderbemittelten als Wohngebiet diente, scheint für die Dichter der Städte eine starke Faszination zu haben.

Goethe schilderte vor beinahe zweihundert Jahren eine Stadt seiner Zeit, vermutich Frankfurt am Main, und seine Zeilen von den 'Vorstädten grenzenlos verlängert' wirken fast wie die Vision einer modernen Stadt:

Krumme Gäßchen, spitze Gibel, Beschränkter larkt Dann weite Plätze, breite Straßen, Vornehmen Schein sich anzumaßen, Und endlich, wo kein Tor beschränkt, Vorstädte grenzenlos verlängt.12 
Das Thema "Vorstadt« wird von den Lyrikern verschiedener Iiteraturrichtungen dargestellt, doch ist für alle das Wort 'Vorstadt' gleichbedeutend mit Elend und Hoffnungslosigkeit, Nietskasernen und niedriger Moral. Je nach Erziehung, Finstellung und Temperament ruft die Vorstadt bei den einzelnen Dichtern Ekel, oder Mitleid hervor. Politisch orientierte Dichter betrachten die Vorstadt als 'Nährboden' für Umsturz und Revolution.

In seinem Gedicht "Der schöne Glockenschlag", das um 1880 entstand, beschreibt Detlev von Iiliencron einen Rundgang durch eine altvertraute Stadt. Der 'reichtönende Klang' der Turmuhr ruft romantische Erinnerungen hervor, aber das Bild wechselt plötzlich, wenn sich der Stadtbummler in die Vorstadt verirrt:

Wo sich in Armut fristen viel tausend Leute; Und dort wie früher fand ich's heute.

Im vierten Stock einer Mietskaserne,

Wo unten eine schlechte Taverne

Gesindel aufsog, wo die Unruhe wohnte, Wo kein Engel die Tugend belohnte,

$\dot{B} \dot{i}$ ins späte Norgenrot

Iärmt draußen das Leben, schluchzt noch die Not.

Und Zank und Zorn, Geschrei, Gelächter;

Einmal Dazwischenkommen der Wächter.

Von einem Tanzsaal her wüstes Gestampf;

Aus der Hölle stieg auf ein greulicher Dampf

Aus Bierbudiken und Schnapsspelunken,

In diesem Dunst schien die Vorstadt ertrunken.13

Arno Holz, einer der ersten Stadtdichter des Naturalismus, war mit den Elendsvierteln der Berliner Vorstädte 
wohlbekannt, da er seit dem zwölften Lebensjahr bis zu seinem Tod in der Reichshauptstadt wohnte. In seinem »Phantasus I« Gedicht, das 1885 erschien, beschreibt er das Leben eines armen, aber inspirierten Poeten im Dachgeschoß einer Mietskaserne und gibt damit zugleich einen Einblick in die Lebensverhältnisse der Vorstadtbewohner:

Ihr Dach stieß fast bis an die sterne, vom Hof her stampfte die Fabrik, es war die richtige Mietskaserne mit Flur-und Leiermannsmusik. Im Keller nistete die Ratte, Paterre gab's Brenntwein, Grog und Bier, und bis ins fünfte Stockwerk hatte das Vorstadtelend sein Quartier. 14

Dem Gedicht »Vorstadt im Föhn«, 1919 von Georg Trakl geschrieben, liegt wahrscheinlich die Vorstadt Wiens zugrunde. Man findet hier nicht die übliche Beschreibung von Mietskasernen, sondern der Dichter schildert das ärmliche Milieu am Stadtrand mit vernachlässigten, 'geduckten' Hütten.

Für Trakl war jede große Stadt 'eine Stätte der Verwesung und der Lebensvernichtung', wie Karl Ludwig. Schneider schrieb.15 Nicht nur die öde und übelrièchende Vorstadt selbst, sondern auch ihre Bewohner rufen Ekel und Grauen hervor:

Am Abend liegt die Stätte öd und braun, Die Luft von gräulichem Gestank durchzogen. Das Donnern eines Zugs vom Brückenbogen Und Spatzen flattern über Busch und Zaun. 
Am Kehrricht pfeift verliebt ein Rattenchor, In Körben tragen Frauen Eingeweide, Ein ekelhafter Zug voll Schmutz und Räude, Kommen sie aus der Dämmerung hervor. 16

Wie ein paar Zeilen aus Georg Heyms Gedicht "Die Vorstadtณ erkennen lassen, datiert vom September 1910, malt der Dichter ein Bild sozialer Not, Verkommenheit, und roher Sitten der Vorstadtmenschen:

In ihrem Viertel, in dem Gassenkot, $\dot{\mathrm{Da}}$ 'sitzen sie die warme Sommernacht Vor ihren Höhlen schwarzer Unterwelt, Im Lumpenzeuge, das vor Staub zerfällt Und aufgeblähte Leiber sehen macht.I?

Ein Gedicht von Johannes Becher, das fast zwanzig Jahre später entstand, zieht einen Vergleich zwischen den Villenvierteln der Reichen und den Mietskasernen der Armen. Der Dichter verbindet damit politische fberlegungen und wirft die Frage auf, Warum sind die einen glücklich wie 'bescherte Kinder', während die andern 'in ihren Löchern ersticken':

Häuser an Häuser, Häuser vor Häuser gebaut, Massige Särge mit Türen und Luken-Manchmal ein Fetzen Himmelblau, Und du kannst in die Sterne gucken. Auf den Höfen dampft Müll

HeiBer Staub

Regnet auf verkrüppelte Eäumchen nieder, Welk ist schon im Sommer das Laub.

Dort wo die Reichen wohnen, Hatte die Stadt ein ander Gesicht. Gärten umspülten die Häuser Mit grünem Iicht.18 
Erich Kästners: . Vorstadtstraßen entstand in den dreißiger Jahren und ist, wie viele seiner Gedichte, in einem ironischen Ton geschrieben. Aber trotzdem übermitteln die Verse die Botschaft des Dichters, der auf die Armseligkeit der Vorstadtmenschen hinweist, die in einer 'kranken' Umwelt hausen müssen:
Die Nacht fällt wie ein großes altes Tuch, von Iicht durchIöchert auf die grauen Mauern.
Ein paar Laternen gehen zu Besuch, und vor den Kellern sieht man Katzen kauern.
Die Häuser sind so traurig und so krank, weil sie die Armut auf den Straßen trafen. Aus einem Hof dringt ganz von Ferne Zank, dann decken sich die Fenster zu und schlafen.19

Bertolt Brecht betrachtet die Vorstadt von einer anderen Perspektive aus. Schon der Titel seines.Gedichtes, »Die ärmeren Mitschüler aus den Vorstädten«, zeigt, daß es Standesunterschiede bereits in der Schule gibt.

Brecht beschreibt nicht die Mietskasernen und dunklen Hinterhöfe, er sieht vielmehr die jungen Menschen, die aus dieser Umgebung hervorkommen. Er schildert ihr Bestreben, sich aus dem Milieu der Armut herauszuarbeiten und eine Bildung zu erlangen, doch ist dieses Bestreben von Anfang an zum MiBlingen verurteilt, denn ein Ubertreten der Klassengrenzen wird nicht geduldet: 
Die ärmeren Mitschüler in ihren dünnen Paletoten Kamen des Morgens immer zu spät in die Stunde

$\mathrm{Da}$ sie ihren Müttern Milch oder Zeitungen austrugen. Die Lehrer

schrieben sie schimpfend in das Tadelbuch.

- $\cdot$.

Wenn sie die Iudolfsche ZahI richt wußten

Fragten die Lehrer sie: Warum

Bleibst du nicht in der Gosse, aus der du kommst?

Aber das wußten sie.20 
WOHNVERHA'ITNISSE

: Oftiwird angenommen, daß vor der industriellen Revolution und Massenflucht in die Stadt das Problem der Wohnungsnot unbekannt war und Neubauten und Einwohnerzuwachs sich die Waage hielten. Jedoch hatten bereits die mittelalterlichen Städte ähnliche Probleme. Da sie sich ihrer beschränkenden Mauern wegen nicht in die Ereite ausdehnen konnten, wurde schon früh damit begonnen, mehrere Stockwerke übereinander $z u$ bauen. Oft mußte der Mauerring erweitert oder in größerem Umkreis eine neue Mauer angelegt werden.2I

Die meisten Stadtmauern fielen der Industrialisierung und der damit verbundenen Vergrößerung der Städte zum Opfer. Jedoch konnten auch die Reihen von Mietskasernen, die zu dieser Zeit aufsprangen, den Zustrom der Menschen nicht fassen, was zu Ưberbevölkerung und erbärmlichen, unhygienischen Wohnverhältnissen führte.

So wuchsest du in dieser Straße hier; Kummergraue, fünfstockhohe Mietskaserne

ruft Gerrit Engelke, der 'Dichter der Fabrikstädte'. in seinem Gedicht »Mietskaserner aus.22

Alfred Wolfenstein, ein Dichter des Expressionismus, schildert die grauen Straßen, in denen die Häuser eine bedrohliche Haltung einzunehmen scheinen. Sein Gedicht 
»Städterk enthält die Worte 'grau geschwollen wie Gewürgte', was der ganzen Atmosphere der Arbeiterwohnviertel etwas Finsteres und Umheimliches gibt,

Dicht wie Löcher eines Siebes stehn Fenster beieinander, drängend fassen Häuser sich so dicht an, daß die Straßen grau geschwollen wie Gewürgte sehn.23

Ernst. Stadler gibt in. "Abendschluß* einen Einblick in ein'Vorstadthaus, Er beschreibt den Arbeits- und Geschäftsschluß am Ende eines langen Tages, wenn erleichterte Menschen hinaus in die Straßen drängen und 'alle Trottoirs' eng mit bunten Blusen und Mädchengelächter vollgepackt sind'. Doch nach dem verbummelten Abend steht die Heimkehr in die enge, ärmliche Familienwohnung bevor, wo alle Freude und Leichtigkeit stirbt:
als warte nicht Heimkehr, Gewinkel schmutziger Vorstadthäuser, zwischen nackte Mietskasernen gekeilt, karges Miahl, Beklommenheit der Familienstube und die enge Nachtkammer, mit den kleinen Geschwistern geteilt, und kurzer Schlaf, den schon die erste Frühe aus dem Goldland der Träume hetzt. 24

Auch mehrere Jahrzehnte später hatten sich die Wohnverhältnisse in den Arbeitervierteln der großen Städte noch nicht gebessert. Hans Herbert Wintgens läßt seine Gedanken in die Kindheit zurückwandern und beschreibt in seinem Gedicht "Im Hof" das winzige. Stückchen asphaltierten 
Hinterhof, das den zahIreichen Kindern der Mietskasernen als Spielplatz dienen mußte:

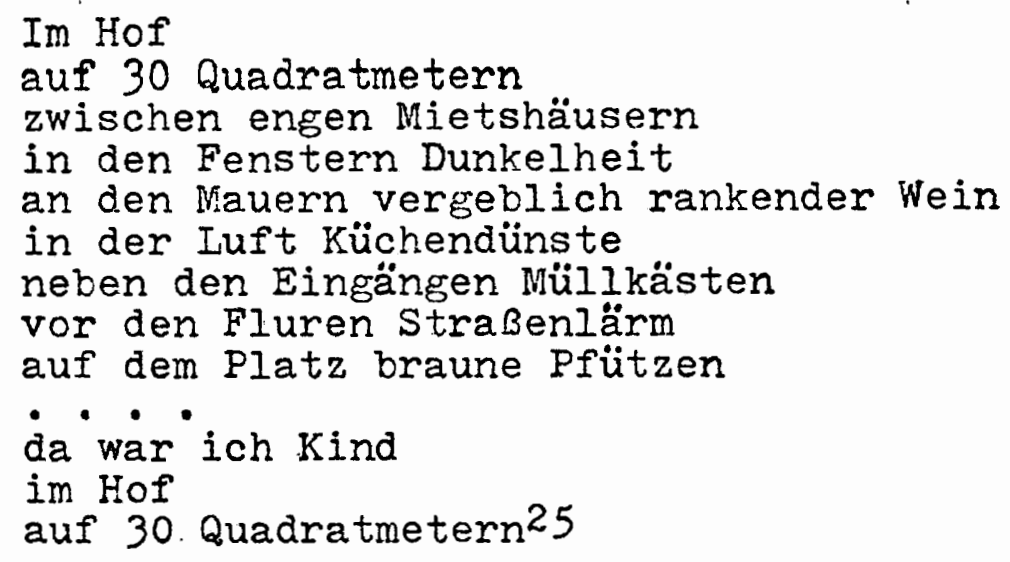

In der stadtlyrik spiegelt sich auch die große Wohnungsnot am Ende des Zweiten Weltkriegs wider, als ganze Stadteile in Ruinen lagen und tausende von Menschen in Behelfswohnungen zusammengepfercht waren.

In "Iagebericht» schildert Iiselotte Rauner die Wohnverhältnisse einer Stadtfamilie, die sich jahrelang mit einer Notbehelfswohnung abfinden muß. Trotz des leichten Tones kann man in dem Gedicht die Verzweiflung der Menschen spüren, die keinen Ausweg mehr sehen:

Wir haben

ein Wohnküchenschlafarbeitszimmer

und zwei Kinder

ich bin im dritten Monat

und habe in meinen vier wänden

keinen Platz mehr für das fünfte Bett wenn in sechs Monaten

das freudige Ereignis eintritt--

ich bin seit sieben Jahren verheiratet und suche seit acht Jahren

eine Wohnung . . .26 
Klaus Stiller schneidet in "Mieter als Vermieter" ein anderes Problem an, das mit der Wohnungsknappheit in den Städten zusammenhängt: die oft unerschwinglich hohen Mieten.

Die Untermieter zahlen mehr als viel, damit die Mieter sich entlasten können. In jedem Fall erreicht der Mietbetrag die Tasche und den Bauch des Hauptvermieters.2?

Auch in der Deutschen Demokratischen Republik hatten sich die Stadtbewohner mit den Problemen der Wohnungsnot zu befassen. Aus Helmut PreiBlers "Neubauten ist zu ersehen, daß der Aufbau zerstörter Städte nach dem Zweiten Weltkrieg nicht schnell genug vor sich gehen konnte. Das Gedicht ist ganz im Sinne des sozialen Realismus geschrieben und betont die baldige Lösung der Probleme:

Leicht schweben Wände empor, fügen sich willig zu Räumen.

Sehnsüchtig schauen die Paare, träumen sich Wohnungen.

Bald hat der Bau ein Gesicht: Lichtaugen, schattenbelebt.

Ich belausch die Familien: Liebe, die Raum hat zu sein.

Städte wachsen sich groß. Heimstatt findet das Glück.

Glück soll dauern. 28 
VERSCHNUTZUNG DER STADDTE UND ENTFREMDUNG DES STADTMENSCHEN VON DER NATUR

Es mag die Stadtbewohner von heute seltsam anmuten, daß eine Stadt jemals als 'groß und reinlich' beschrieben wurde, jedoch finden sich diese Worte in Goethes Gedicht Hermann und Dorothea. Hermanns Vater empfiehlt seinem Sohn die Städte Mannheim, Frankfurt und Straßburg als sehenswerte Reiseziele und fährt fort:

Denn wer die städte gesehn, die großen und reinlichen, ruht nicht,

Künftig die Vaterstadt selbst, so klein sie auch sei, zu verzieren.29

Die Verschmutzung der Stadt ist ein Thema, das immer wieder in der Dichtung in Erscheinung tritt, mag es sich um qualmende Fabrikschlote, verseuchte Stadtluft und Wasserwege, oder schmutzige Grünanlagen handeln.

In Morgense schildert Jakob van Hoddis eine Szene aus seiner Heimatstadt Berlin, wo die frühe Morgensonne ein trübseliges Bild erhellt.

Die Morgensonne rußig. Ảuf Dämmen donnern züge. $\dot{D}$ ampfe $\dot{r}$ und Kräne erwachen am schmutzig fließenden Strom. 30

Oskar Kanehls "Kanalbrücke Eerlin», ebenfalls 1914 entstanden, bestätigt diese Eindrücke von der Berliner 
Hafenlandschaft. Das Wasser ist verseucht, und die Natur 'schweigt', weil sie am Absterben istr:

Dunstäugig schauen die Ufer
und schweigend sich an.
Wasser voli Dreck und ol.
Schleppdampfer. Kahn und Kahn. 31

Ernst Stadlers Gedicht "Dämmerung*, erschienen 1902, beschreibt eine Großstadt im Dämmerlicht des Abends. Aber der sanfte Schein der letzten Sonnenstrahlen vermag nicht, die negativen Seiten der Stadt $z$ mildern oder zu verbergen:

Schwer auf die Gassen der Stadt fiel die Abenddämmerung. Auf das Grau der Ziegeldächer und der schlanken Türme, Auf Staub und Schmutz, Lust und Leid und Lüge der Großstadt. 32

Georg Heyms "Die Schatten I* schildert den düsteren Teil einer großen Stadt, der schmutzig und finster daliegt. Es ist charakteristisch für Heyms Stadtgedichte, daß sie das Unheimliche, Furchterregende beschreiben, das lauernd im Hintergrund liegt:

In mancher Tore finstere Bogen,
In rauchende Straßen
Und schmutzige Städte,
Uber dunkelnde Gassen geduckt 33

Die Verschmutzung der großen Industriestädte des Ruhrgebiets wurde besonders von den sogenannten Arbeiterdichtern angeprangert. Man zählt zu ihnen Paul Zech, 
Karl Eröger, Josef Winckler, Johannes Becher, Otto Wohlgemuth und andere. Paul Zechs Verse tragen den Titel »Park an der Fabrik火, jedoch fällt der Park der Umweltverschmutzung zum opfer und die Natur ist 'krank":

Aber hier ist jedes Blatt schon angefressen vom Zerfall und jeder Halm so wurzelkrank, daß im Mai die Knospen das Gefühl des Elühns und die Wiese einschrumpft vor Gestank. 34

Ahnliche Gedanken drückte Rainer Maria Rilke bereits 1903 in einem Aufsatz aus, in dem er von der städtischen 'Unnatur' spricht, die das Erwachen der Natur im Frühling nicht mehr zuläßt, »Wir ersticken.. . . mit dem Pflaster unserer Städte wundervolle Frühlinge, die bereit waren, aus den Krumen zu steigen."35

Bertolt Brecht weist in "Städtische Landschafte darauf hin, daß die Verschmutzung von den Stadtbewohnern selbst zum großen Teil verursacht wird:

Die Menschenströme

Uberfüllen die Geschäftsviertel

Die in der Nacht gesäubert wurden

Von dem Schmutz und den Verheerungen

Der Mienschenströme

Vom Tag vorher. 36

Eịne Dichterin aus dem westdeutschen Industriegebiet, Marlene Vehrings, weist in ihrem "Wiegenlied" auf die schädlichen Abgase, welche besonders die Gesundheit der Kinder in den großen Städten gefährden: 


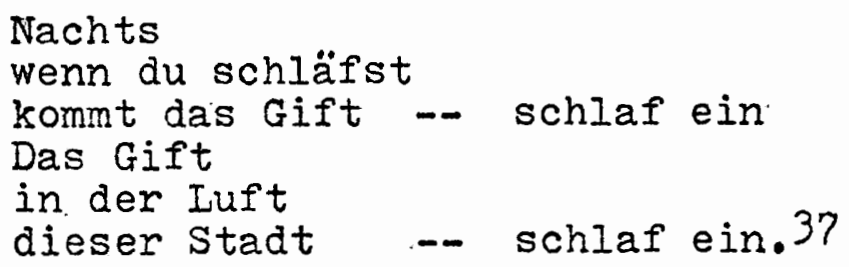

Arno Reinfrank greift das gleiche Thema auf in "Mutation«, wo er von den bis jetzt noch unabwägbaren Folgen der chemischen Verunreinigung der Stadtluft spricht:

In den Straßen unserer städte aber lagert Abgasgift von Industrien und Motoren oxydule, deren Folgenschwere niemand abwägt. 38

In seinem Gedicht "Frankfurt" schreibt Hans Kaspar über einen Vorfall aus dem Jahre 1957, als tausende von toten Fischen im Main in der Nähe Frankfurts gefunden wurden:
Zehntausend Fische erstickten im öligen Main.
Kein
Grund für die Bürger der Stadt zu erschrecken. 39

Er fährt in ironischen Ton fort, daß die schnelle Strömung des Flusses die 'silbernen Leichen der Fliegengeschmückten' bald hinwegtrug und nun 'alles wieder aufs Beste geordnet ist'. Reinfranks Gedicht ist eine Anklage gegen die Nachlässigkeit der Industrie und Stadtbehörden, aber er beschuldigt auch die Stadtbewohner wegen inrer Gleichgültigkeit.

Rolf Dieter Brinkmann prangert in "Programmschluß * 
gerade diese Gleichgültigkeit an, die die Verunreinigung der schönsten Stadtparks zuläBt oder sie sogar selbst verschuldet:

Jetzt zieht eine kühlere Iuft durch den Park und macht das wenige Grün schwarz, das eine schmutzige Collage ist aus Hundekot, alten Zeitungen, Zigarettenschachteln, und einem ausgelatschten Halbschuh. 40

Jedoch ist nicht nur die Verschmutzung der städte beklagenswert, sondern vor allem die Entfremdung des Großstadtmenschen von der Natur. Schon vor der Jahrhundertwende rief Richard Dehmel in "Predigt ans Großstadtvolk« den Menschen zus

Geht doch hinaus und seht die Bäume wachsen . . Ihr steht und schafft Euch Zuchthausmauern-so geht doch, schafft Euch Land! Land: rühṛt Euch: 41

Viele Lyriker geben ihrer Trauer und Besorgnis darüber Ausdruck, daß sich der Stadtmensch so ganz den Versuchungen und Vergnügungen der Stadt hingibt und den Sinn für die Schönheit der Natur verloren hat. Heinz Kahlau spricht darüber in "Allein* und bedauert die Naturabgewandtheit des modernen Menschen:

Zwischen Tieren sind wir jetzt schon Fremde. Zwischen Gräsern, zwischen Bäumen auch. Fremd ist uns der Erdgeruch der Moose. Uns verwirrt der Wind. Des Regens Hauch. 
Unsere Iiebe ist zuhaus in Städten.

Ihre Iandschaft läßt uns sorglos sein.

$Z$ wischen ihren Iärmen und Gerüchen

fühlen wir uns sicher. Und allein. 42

Ein Gedicht von Klabund mit dem bezeichnenden Titel "Proleten schildert die Lebensverhältnisse einer Arbeiterfamilie in der 'feuchten Grube' einer Mietskaserne, wo das Wort 'Natur' beinahe absurd klingt. Die Menschen kämpfen um ihre Lebensexistenz, die aliein für sie von Wichtigkeit ist:

In dem Sausen der Maschinen,

In dem Fauchen der Fabrik,

Wo sind Berg und Reh und Bienen

Und der Sterne Goldmusik?

Unser ohr ist längst verstopft. . • Hämmer klopft, Hämmer klopft. $43^{\circ}$

Gerrit Engelke bringt in "Ich will hinaus:" den Wunsch des.Stadtmenschen zum Ausdruck, sich aus Enge und Gebundenheit $z u$ befreien und in der Natur Erfüllung und Befriedigung $\mathrm{zu}$ suchen:

Hinweg von Märkten, Zimmern, Treppenstufen, Straßenbraus --

Die Waldberge, die Waldberge rufen, Locken mich hinaus:

Bald hab' ich diese Straßenwochen, Bald diesen Stadtbann aufgebrochen Und ziehe hin, wo Ströme durch die Ewig-Erde pochen, Ziehe selig in die Welt: 44 
Die jungen Lyriker der Gegenwart zeichnen aber den Großstadtmenschen als ein unwiderruflich von der Natur entfremdetes Wesen. Für Heike Doutiné ist der Stadtbewohner ein Produkt der Technik, ein 'Neonmensch', der wie ein Robot seine tägliche Routine durchläuft. Er ist der Natur entfremdet und hat auch kein Verlangen mehr, zu ihr zurückzukehren. Die Dichterin schließt ihr Gedicht "Transparentณ, das 1970 erschien, mit der Feststellung:

Durch die Pulsadern der Städte an die Arbeit, zu den Neonmenschen.

Nachts lallen sie in ihren Zimmern, nachts dampfen sie die Tage aus. Aber im Iichte packen sie stumpf ihre Taschen, kommen wieder. 45 


\section{DER IARM DER GROBSTADT}

In einem alten englischen Gedicht kommen die Zeilen vor:

Hell is a city much like London, A populous, noisy and smoky place. 46

Die gleiche Beschreibung dürfte für die meisten großen Städte zutreffend sein, denn ohrenbetäubender, fast niemals endender Lärm ist das 'Wahrzeichen' der modernen Großstadt.

Man kann sich eines Iächelns nicht erwehren, liest man die Beschreibung des nächtlichen Straßenlärms einer Stadt um 1750, wie sie in Lessings Lustspiel Minna von Barnhelm gegeben ist. Voll Empörung beschwert sich Franziska über die Störung inrer Nachtruhe:

Wer kann in den verzweifelten großen Städten schlafen? Die Karossen, die Nachtwächter, die Trommeln, die Katzen, die Korporale--das hört nicht auf zu rasseln, zu schreien, zu wirbeln, zu mauen, zu fluchen; gerade, als ob die Nacht zu nichts weniger wäre, als zur Ruhe.47

Hundert Jahre später wurḍen die Straßengeräusche von den ersten Dampflokomotiven, Fabriksirenen und klappernden Pferdeomnibussen verursacht. Der Fortschritt der Technik läßt sich also am Iärm und den Geräuschen einer Stadt verfolgen. 
Bereits in den Stadtgedichten der französischen Lyriker des neunzehnten Jahrhunderts findet der Lärm der Großstadt Erwähnung. So schreibt Charles Baudelaire in seinem Gedicht "'̀ une Passante«, La rue assourdissante autour de moi hurlait.

Walter Benjamin übersetzte diese Zeile folgendermaßen: Geheul der Straße dröhnte rings im Raum. 48

Auch in den ersten deutschen Stadtgedichten vor der Jahrhundertwende findet man bereits die verschiedenartigen Töne und Geräusche der Stadt beschrieben. In "Die Stadt» schildert otto zur Linde die Vorgänge im Hinterhof einer Mietskaserne samt den dissonanten Tönen, die dort widerhallen:

Kinder spielen lärmend im Hof;

Den Schall des Teppichklopfens werfen die Wände zurück, Er sucht den Ausgang aus engem Hof und findet offne Fenster. Aus der Tür der Kellerwohnung Hämmern des Schumachers; Rufe des Kohlenmanns, und noch so manches Händlers
Das alles brodelt im großen, tiefen Topf des Hofs. 49

Die bis zum Ende des neunzehnten Jahrhunderts üblichen kleinen Hinterhoffabriken trugen ebenfalls ihren Teil zum Straßenlärm bei. In "Phantasus III» beschreibt Arno Holz das Pochen und Hämmern einer solchen Fabrik, deren Iärm auf die Nerven geht:

Vom Hof her poltert die Fabrik und walkt unä stampft und pocht und hämmert, ein hirnzermarterndes Gequiek. 50 . 
Während die Dichter des Naturalismus den Stadtlärm als etwas Natürliches, wenn auch Unerwünschtes darstellen, empfinden ihn die Iyriker des Expressionismus als ein 'Nervenerlebnis'. Im Juni 1911 erschien in der Zeitschrift Die Aktion ein Aufsatz von Arthur Silbergleit unter dem Titel "Die Stimme der Stadt, worin er schreibt, daß die tausend Straßenlaute einer Großstadt wie ein 'Choral der Straßen, wie mystische Musik' klingen. Er fährt fort:

Und wo findet Ihr so viel Blut, Rausch und Seele, so viel Schicksalstanz und Abenteuer, Kampf, Schönheit und Magie, eine so wundervolle sinfonia heroica als in den oft verlästerten Riesenstädten?5I

In 》Sonntagnachmittag《 beschreibt Alfred Lichtenstein die dissonanten Töne, die an diesem Feiertag durch die Straßen hallen und die Ruhe stören:

Wie Schreibmaschinen klappern Droschkenhufe. Und lärmend kommt ein staubger Turnverein. Aus Kutscherkneipen stürzen sich brutale Rufe. Doch feine Glocken dringen auf sie ein.

In Rummelplätzen, wo Athleten ringen, Wird alles dunkler schon und ungenau. Ein Ieierkasten heult und Küchenmädchen singen. Ein Viann zertrümmert eine morsche Frau. 52

Ernst Stadler erwähnt in einem Gediabt aus dem Jahre 1913 den 'Donner der Automobile', der den Menschen dieser Zeit bereits unerträglich, aber gleichzeitig auch faszinierend erschien. Votorengeräusche waren seit dieser Zeit ein Teil der 'Iärmsymphonie' der Großstadt. 
Ein Grammophon quäkt auf, zerbrochne Weiberstimmen knarren,

Und fern erdröhnt die Stadt im Donner der Automobile. 53

Jedoch wurden die Geräusche der großen Stadt von vielen Dichtern nicht als störender Iärm, sondern als ein Zeichen des pulsierenden Lebens dargestellt. Bereits der Titel von Leo Sternbergs Gedicht »Du schönernIärm des Lebens« bestätigt seine positive Einstellung. Er schrieb im Jahre 1916:

Du schöner Lärm des Lebens--

dich hör ich wieder. Auf gepflasterten Straßen das Getrappel sich eilig überholender Menschenfüße; die Ketten der Uferkranen rasseln; und sich kreuzende Schnellzüge rasen donnernd vorüber. 54

Besonders für die Arbeiterdichter der Industriegebiete war der Iärm der Fabriken und Städte ein Zeichen des Fortschritts. Willy Bartok spricht vom' 'Kreischen der Fördertürme', das wie Musik im 'Orchesterbild des Reviers' klingt. Otto Wohlgemuth schreibt in "Industriegebiete:

Telegraphendrähte harfen bei Nacht,

Erdpuls zittert und pocht in den wä̀nden 55

Die vielen verschiedenartigen Geräusche einer Großstadt faszinieren auch die Dichter der Gegenwart. Allerdings werden die Töne nicht als 'Musik' und 'Symphonie des Iebens' empfunden, sondern als 'irrer Lärm', wie sich 
Rolf Brinkmann in "Programmschluß» ausdrückt:

- . unverwandt nach draußen sehen auf Iastwagen, $\dot{V}$ oikswagen, Kinderwagen, Straßerbahnen und Busse, die stinkend vorüberfahren mit irrem Iärm. 56

In 》Großstadtkavalkades stimmt Wilhelm Adametz dieser Ansicht bei. Auch er empfindet den Lärm, der nur $\mathrm{ab}$ und $\mathrm{zu}$ eine Dämpfung erfährt, als unerträglich und nervenaufeibend:

Getöse, Kreischen, Nervensägen. Betonorchester ohne Gnade. Reklameschlacht mit Keulenschlagen. Nur manchmal dämpft ein milder Regen

Den Lärm der Großstadtkavalkade. 57 


\section{KIASSENUNTERSCHIEDE UND SOZIAIES EIEND}

Klassen- und Standesunterschiede sind so alt wie die Menschheit selbst. Nirgends treten sie aber so kraß in Erscheinung wie in der großen stadt.

In einem Brief an Eckermann, datiert vom 12.Nai 1828, schreibt Goethe über die sozialen Verhältnisse der Städte Anfang des neunzehnten Jahrhunderts :

Aber gehen sie einmal in unsere großen städte, und es wird Ihnen anders zumute werden. Halten Sie einmal einen Umgang, . : und Sie werden über das Elend erschrecken und über die Gebrechen erstaunen, von denen die menschliche Natur heimgesucht ist und an denen die Gesellschaft leidet. 58

Die sozialen Mißstände und krassen Klassenunterschiede, die sich mit Beginn der industriellen Revolution noch wesentlich vergrößerten, haben bereits in der frühen deutschen StadtIyrik Ausdruck gefunden. Die Dichter des Naturalismus prangerten nicht nur die elenden Lebensverhältnisse der unteren Klassen an, sondern schilderten auch die damit verbundenen moralischen Probleme.

Die verächtliche Einstellung der oberen Klassen gegen die Besitzlosen wird von Arno Holz in "Phantasus IIIR, das 1886 entstand, beschriebens

Die Ritter von der engen Taille, das sind die schlimmsten aus dem Korps, sie schimpfen hündisch dich "Kanaille* und haun dich schamlos"übers Ohr. Was kümmert sie's, wenn Millionen verreckt sind hinterm Hungerzaun?59 
Aber nicht nur die Aristokratie, auch die gewöhnIichen Bürger der Stadt fühlten sich über den Lohnarbeiter erhaben. Bruno Wille schildert in seinem Gedicht "Straßen«, das 1908 erschien, den Hochmut der eingebildeten Bourgeoisie:

Nun heult vom Hofe die Maschine

Zur Vesper; da entläßt das Tor

Viel arbeitsmatte Blusenmänner;

Nur der Fabrikschlot stößt empor

Zum roten Monde schwarzen Rauch.

Ein würdiger Bürger kommt geschritten,

Den Iump am Steige trifft sein Blick;

Entrüstet mit dem Kopfe schüttelnd

Geht er zu Bier und Politik.

Und zornrot glüht der volle Mond.60

Auch Rainer Maria Rilke hat sich mit dem Thema der sozialen Mißstände befáßt, doch unterscheidet sich seine Darstellungsweise von der Bruno Willes. In den Gedichten in Das Buch von der Armut. und vom Tod beklagt sich der Dichter darüber, daß Gott solches Elend der Menschen zuläßt, ohne zu helfen. Rilkes Gedicht "Denn, Herr, die großen Städte«, das am 14. April 1903 entstand, beklagt die Entmenschlichung und Hoffnungslosigkeit der Armen in den großen Städten:

Denn, Herr, die großen Städte sind Verlorene und Aufgelöste; wie Flucht vor Flammen ist die größte,und ist kein Trost, daß er sie tröste, und ihre kleine Zeit verrinnt. $\mathrm{Da}$ leben Menschen, leben schlecht und schwer, in tiefen Zimmern, bange von Gebärde, geängsteter denn eine Erstlingsherde; und draußen wacht und atmet Deine Erde, sie aber sind und wissen es nicht mehr.6I 
Auch Erich Kästner befaßte sich in seinen Gedichten der zwanziger Jahre mit den sozialen Verhältnissen in der Stadt. In "Vorstadtstraben gibt er einen Einblick in die Berliner Arbeiterviertel Moabit und Wedding, in denen man schon aus den Küchend ü:nsten die Armut der Bewohner erahnen kann:

$$
\begin{aligned}
& \text { Mit solchen Straßen bin ich gut bekannt. } \\
& \text { Sie fangen an, als wären sie zuende. } \\
& \text { Trinkt Magermilch: steht groß an einer Wand, } \\
& \text { als ob sich das hier nicht von selbst verstände. } \\
& \text { Es riecht nach Fisch, Kartoffeln und Benzin. } \\
& \text { In diesen Straßen dürte niemand wohnen. }
\end{aligned}
$$

Auch die ungesunden und unhygienischen Lebensverhältnisse der unteren Klassen kommen in vielen Gedichten zur Sprache. In "Helles Iied aus dunklem Hof* beschreibt Erich.Weinert eine Kellerwohnung, in der die Armen inr Leben fristen und von Krankheiten aufgezehrt werden:

Es dampft aus den Kellern, der Müllkasten stinkt, Die Brandmauer schimmelt vor Nässe. Der Wind, der über die Dächer springt, Wirft Qualm herab aus der Esse. Es blättert der Putz wie Schorf von der Wand. Hier haust, in naßkalte Löcher verbannt, Die Schwindsucht, die Not, und der Jammer. 63

Es ist nicht verwunderlich, daß sich vor allen Dingen politisch orientierte Dichter mit den sozialen Mißständen in den Städten befaßsten. Armut brütet Unzufriedenheit, und Unzufriedenheit kann der Anstoß zu politischem Umsturz sein. Johannes Bechers Gedicht "Stein* soll hier als 
Prototyp angeführt werden für die vielen, die die Not der Arbeiter in den großen Industriestädten beschreiben und die oft gleichzeitig eine politische Botschaft enthalten. Becher läßt in seinem Gedicht einen Fabrikarbeiter sprechen, der den Massen in die stadt gefolgt und nun arbeitslos geworden ist:

Ich lebe in der großen Hungerstadt.

Was iBt ein Stein? Ein Stein wird satt Auch von der Iuft, die voll ist von Geruch. Ein Stein ist nackt. Er braucht als Kleid kein Tuch. vielleicht hebt dieser stein sich einmal auf. 64

Auch Klabund befaßt sich mit dem Los des Arbeiters. In "Proleten beschreibt er die erbärmlichen Wohn- und Lebensverhältnisse einer Familie und betont ihre Hoffnungslosigkeit und Resignation, jemals ihr Schicksal verbessern zu könnens

Sieben Kinder in der Stube Und dazu ein Aftermieter, Hausen wir in feuchter Grube, Und der blaue Tag--o sieht er Uns, verbirgt er sein Gesicht. Gebt uns Iicht, gebt uns licht:

Und so kriechen unsre Tage

Ekle Würmer durch den Keller, Und wir hungern, und wir klagen Nie: schon pfeift die lunge greller; SchmeiBt die Schwindsucht uns in Scherben, Laßt uns sterben, laßt uns sterben: 65 
Mit der Besserung der sozialen Verhältnisse durch Schaffung und Durchführung neuer Gesetze, verschwand der Aspekt der Klassenunterschiede und des sozialen Elends aus der deutschen Stadtyrik. 
NACHTLEBEN UND DEKADENZ IN DER GROBSTADT

Schon immer wurden Städte als Stätten loser Moral und vieler Untugenden bezeichnet, ganz gleich ob es sich dabei um die kleinen Städte, des Mittelalters oder moderne Großstädte handelt. Wird aber in kleineren Orten oft der Versuch gemacht, die menschlichen Schwächen zu verbergen und den Schein zu wahren, so treten sie in den großen Städten oft hemmungslos zutage.

Rousseau sagte Mitte des achtzehnten Jahrhunderts: "Les villes sont le gouffre de l'espèce humaine*.66 Diese Ansicht wurde von anderen berühmten Nännern geteilt. So offenbart Nietzsche seine Gefühle über die Lasterhaftigkeit in den Großstädten in Also sprach Zarathustra:"Alle Iüste und Laster sind hier zu Hause." Auch der Stadtmensch in all seiner sündhaftigkeit ist in diesem Werk beschrieben:

Hier fließt alles BIut flaulicht und laulicht und schaumicht durch die Adern:

speie auf die große Stadt

welche der große Abraum ist, wo aller Abschaum zusammenschäumt. 67

Wilhelm Busch schrieb zur selben Zeit, im Jahre 1882, das humorvolle Gedicht von der frommen Helene; das einen Einblick in die Städte dieser Zeitepoche gewährt. In den Versen "Lenchen kommt aufs Land" heiBt es:

Wie der wind in Trauerweiden Tönt des frommen Sängers Lied, Wenn er auf die Lasterfreuden

In den großen städten sieht. 68 
Unter dem Einfluß des Naturalismus wurden in der deutschen Iiteratur solch heikle Themen wie Vergnügungssucht und Sittenlosigkeit zum ersten mal aufgegriffen. Albert Sörgel erwähnt, daß um 1880 zum ersten mal Wörter wie 'Hure' und 'Prostitution' in der deutschen Lyrik erschienen.

In einem Gedicht Detlev von Iiliencrons, das noch vor der Periode des Naturalismus entstand, ist die Zurückhaltung in der Wahl der Worte erkennbar. In $"$ Der schöne Glockenschlag» beschreibt er eine nächtliche Vergnügungsszene in der Vorstadt, 'Wo kein Engel die Tugend belohnte':

Wo unten eine schlechte Taverne Gesindel aufsog, wo die Unruh wohnte, Wo kein Engel die Tugend belohnte, $\mathrm{Da}$ hab' ich einmal eine kurze Nacht

In Iiebesüberschüttung zugebracht.69

In Arno Holz'. "Großstadtmorgen tritt bereits die neue freie Ausdrucksweise in Erscheinung. Er scheut nicht davor zurück, auch bisher 'unerlaubte' Wörter zu gebrauchen und sozusagen 'das Kind beim Namen zu nennen'?

da schritt ich müde durch die Friedrichstadt, bespritzt von ihrem Schmutz bis in die Seele. Kein Quentchen Ekel war in mir erwacht, wenn mich die Dirnen schamlos angelacht?

In den Gedichten des Expressionismus wird oft auf diese Schattenseite der Großstadt hingewiesen, auf die verkäufliche Liebe und die damit verbundenen Probleme. Obwohl der Sittenverfall beklagt wird, ist doch aus vielen Gedichten Mitleid 
und MitgefühI herauszuspüren. Die Prostituierten; diese Ausgestoßenen der menschlichen Gesellschaft, können nicht allein für ihr Schicksal verantwortlich gemacht werden. Ein großer Teil der Schuld ruht bei der Gesellschaft und den Zeitverhältnissen.

In. "Die Nacht" schildert Alfred Iichtenstein eine Straßenszene, die des Dichters Sympathie und Empathie durchblicken läßt:

Um harte Häuser humpeln Huren hin und wieder, Die melancholisch ihren reifen Hintern schwingen. Viel Himmel liegt zertrümmert auf den herben Dingen Wehleid'ge Kater schreien schmerzhaft helle Lieder.7i

Wie viele Dichter des Expressionismus, experimentiert auch Paul Boldt mit neuen Ausdrücken, Metaphern, und einem neuen Stil. Doch auch sein Gedicht \&Stadt III* zeigt Verständnis für die 'Iosen Mädchen' :

Wind fliegt vorbei als dunkler Pferdeschweif. Und Hurenlächeln brennt am Kleiderdocht.

Tagestrottoir beschreiten Dunkel Träger. Kleider mit alten Flecken roten Munds. Antiti, auf Hirn gefaltet, friert blutlos.72

August Stramms "Freudenhausk, das er 1912 schrieb, zeigt den für Stramm typischen abgehackten Sprachstil mit neuen Wortbildungen. Das Gedicht deckt die unhygienischen Zustände in einem Haus der Prostitution auf und weist auf die Verwerflichkeit solcher Häuser hin: 
Iichte dirnen aus den Fenstern

die Seuche

spreitet an der Tür

und bietet Weiberstöhnen aus:

Frauenseelen schämen graue Iache:

Mutterschöße gähnen Kindestod:

Ungeborenes

geistet

dünstelnd

durch die Räume:

Scheu

im WinkeI

schamzerpört

verkriecht sich

das Geschlecht:73

Fast zur gleichen Zeit, im Jahre 1914, schrieb Johannes Becher ein 24-strophiges Gedicht mit dem Titel "Die Hurenk. Er richtet darin eine dringende Warnung an alle Mütter: Wahret euere Söhne in den Häusern: Der Dichter prophezeit, daß die Huren Verderbnis über die Menschheit bringen und am Untergang ganzer Städte schuldig sein werden:

Die Huren werden grinsend euere Einsamkeit belauern. Die Huren werden euch in böser Träume Schlaf erwürgen. Die Huren werden um die Kindheit furchtbar opfernd trauefn. Die Huren werden euerer Städte gläsernen Bau zerwirken. 74

Aber nicht in allen stadtgedichten wird das Thema der Dekadenz so drastisch und düster dargestelzt. In den dreiBiger Jahren entstanden Gedichte, die einen leichteren, mehr oder wenig ironischen Ton aufweisen. Trotzdem sind sich aber die Dichter der Schwere und Weitläufigkeit des Problems bewußt.

In eBesuch vom Lander schildert Erich Kästner die naiven Leute vom Dorfe, die bei ihrem ersten Besuch in der 
Großstadt nicht nur vom Verkehr und Iichterglanz, sondern vor allem von dem Mangel an Tugend in Schock versetzt werden:

Sie stehen verstört am Potsdamer Platz.

Und finden Berlin zu laut.

Die Nacht glüht auf in Kilowatts.

Ein Fräulein sagt heiser:"Komm mit,mein Schatz: "

Und zeigt entsetzlich viel Haut.75

Auch in Kurt Tucholskys "Lied von der Gleichgültigkeite ist die Hure repräsentativ für die moralische Verkommenheit und Lasterhaftigkeits

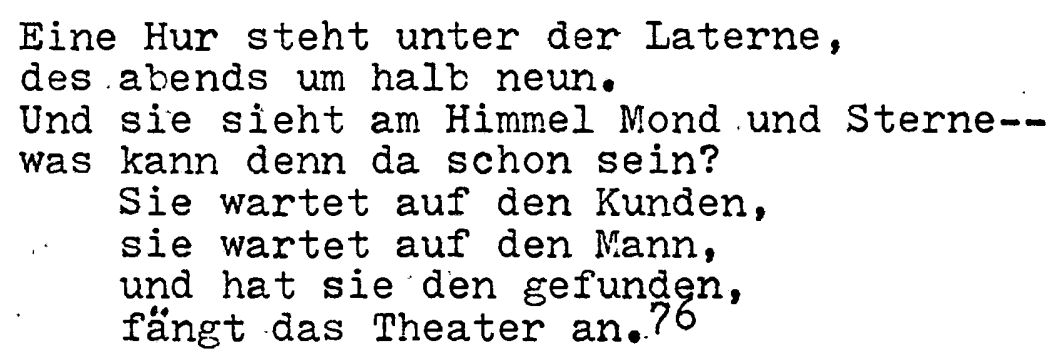

Auch Dichter unserer Gegenwart befassen sich mit dem Thema der Dekadenz in den Städten. Kurt Bartsch stellt das Problem der Prostitution auf eine deskriptive und rückhaltslose Weise dar, wie die erste Strophe seines Gedichts "Berline zeigt:

die straßen grün, ein violettes mädchen hält sich an mauern auf und ist geöffnet; ein buchhalter, kurzfristig, füllt sie aus.7?

Ein noch unbekannter junger Dichter unserer Zeit, Horst Lehner, stellt das Problem in "Zeit ein Gedicht zu machen auf eine mehr diskrete Weise dar: 
Straßennächte sind Höhlen

Sie enden im Anfang

Kreisen in der Knochenbleiche von Glühbirnen Mond für Falter

und Laternenmädchen78

Das Thema "Nachtleben und Dekadenz in der Großstadte, das von den Dichtern des Westens frei und ohne Zurückhaltung dargestellt wird, findet in der Iyrik der Deutschen Demakratischen Republik keinerlei Erwähnung.

Gewiß haben die Städte dieses: Landes ähnliche Probleme wie all die andern großen städte der Welt, doch es läßt sich nicht mit der Weltanschauung der DDR vereinbaren, Probleme dieser Art in der Lyrik darzustellen. 
DER IIENSCH IN DER GROBSTADT

\section{Seine Einsamkeit und Furcht}

Die Einsamkeit des Großstadtmenschen und die damit verbundene Unsicherheit und Furcht sind zeitlose, universelle Probleme, die in der stadtlyrik immer wieder auftreten.

Schon 1887 wies der Soziologe Ferdinand Tönnies in Gemeinschaft und Gesellschaft darauf hin, daß die verbindende Gemeinschaft bej den Menschen der großen Städte sich immer mehr auflöst und eine unpersönliche Gesellschaft an ihre Stelle tritt. Wie von vielen Psychologen und Soziologen unserer Zeit bestätigt wird, hat diese Entwicklung drastische Folgen. Viele Menschen der Großstadt empfinden eine innere Leere und tiefe Einsamkeit. Sie scheinen in der Masse unterzugehen und ihre Identität zu verlieren.

Diese Erkenntnis ist jedoch keineswegs unserem Zeitalter zuzuschreiben. Ein altes Sprichwort lautet, Magna civitas, magna solitudo.

Vor rund hundertfünfzig Jahren brachte Franz Grillparzer in seinem Trauerspiel Libussa ähnliche Gedanken über den Stadtmenschen und seine Einsamkeit zum Ausdruck, wenn er Iibussa sagen ließ: 
Doch sind die Menschen strenggeschiedne Wesen, ein Jeder ist ein andrer und er selbst;

Die enge Nähe, störende Gemeinschaft

Schleift $a b$ das Siegel jeder eignen Geltung,

Statt Menschen hast du. Viele, die sich gleich.l

Bereits in der französischen Städtelyrik, die älter ist als die deutsche, findet man diese schwer zu beschreibende innere Einsamkeit des Stadtmenschen erwähnt. Charles Baudelaire spricht von 'ennui', das den Stadtmenschen überkommt und nicht mit 'Langeweile' verwechselt werden darf, wie Heinz Rölleke warnt.2

Schon die ersten deutschen Stadtgedichte befassen sich mit dem Thema der Einsamkeit. Otto zur Iinde klagt in »Stadt und Iandschafte, das um 1880 entstand,

Im hohen Haus der Stadt, über Straßen, Sinnt meine Einsamkeit eng umbaut. Ehe der Traum hebt Dach und drückendes Denken, Dringt der Iärm dumpf auf an mein Ohr und Elend.3

Detlev von Iiliencron wendet sich in seinem Gedicht "In einer großen Stadt" gegen die Gleichgültigkeit der Menschen, die nur an sich selbst denken und keinen Anteil am Schicksal des Nächsten nehmen:

Es treibt vorüber mir im Meer der Stadt Bald der, bald jener, einer nach dem andern. Ein BIick ins Auge, und vorüber schon. Der Orgeldreher dreht sein Iied.4

Ludwig Scharf drückt in "Begegnis» dieselben Gedanken aus. Der Mensch unserer Zeit ist einsam und vermag 
nicht, sich seinen Mitmenschen anzuvertrauen:

Fremd zogen sie aneinander vorbei

Nit großen begegnenden Blicken

Und geschlossenem Mund, ein jeder für sich,

Ein jeder mit seinen Geschicken. 5

Nicht einmal die jungen Menschen sind vor der Einsamkeit gefeit, wie Ernst Stadlers "Abendschluß« zeigt. Er malt ein Bild vom bunten Treiben in den Straßen einer Großstad, fährt dann aber fort:

Und selbst die Glücklichsten, die leicht mit schlankem Schritt

Am Arm des Iiebsten tänzeln, tragen in der Einsamkeit der Augen einen fernen schatten mit.

Zahllose Gedichte, die während der Zeit des Expressionismus entstanden, weisen auf die geheime innere Furcht des Stadtmenschen hin. Gustav Renner sagt in seinem Gedicht »In der Großstadt《:

Stets bin ich einsam, doch am einsamsten, wenn mich des Menschenstroms Wogen tragen durch drängend volle Straßen großer Städte.?

Alfred Wolfenstein experimentierte in "Städter" mit neuen Ausdrucksformen, jedoch bleibt der Grundgedanke derselber die Vereinsamung des Großstadtmenschen:

Und wie still in dick verschlossener Höhle, ganz unangerührt und ungeschaut steht ein jeder fern und fühlt alleine. 8 
Auch die Arbeiterdichter der Industriestädte erwähnen das Phänomen der Einsamkeit. Tausende von Menschen gehen täglich zur gleichen Arbeitsstätte, stehen hinter den gleichen Maschinen und haben dieselben Sorgen, und doch bleiben sie sich innerlich fremd.

In "Fabrikstadt Tags", das 1922 geschrieben wurde, sagt Paul Zechı" Streift ein Mensch dich, trifft sein Blick dich kalt, bis ins Mark. \&9

Aus der Lyrik der Gegenwart ist zu ersehen, daß das Problem der Einsamkeit des Stadtmenschen mehr als je zuvor akut ist. In "Morgenfurchte schreibt Heinz Kahlau, daß die innere Sicherheit und das Selbstbewußtsein des Menschen durch das Gefühl der. Verlassenheit untergraben werden können:

Auch eine Großstadt kann so leer wie eine Kirche sein. Wenn sich der Morgen vor den Fenstern krümmt und nur die Vögel in den Höfen schreih. Dann frage ich mich oft, ob es noch stimmt mit meiner selbstbewußten Sicherheit. Dann bin ich manchmal so weit, daß ich mich wieder fürchten könnte wie ein Kind, das in den Nächten nach der Mutter schreit, weil alle Dinge ringsum fremd und voller Grauen sind. ${ }^{10}$

Ingelux Thomas macht in "Blinde Stadt" die Voraussage, daß die Vereinsamung weiterhin fortschreiten wird, bis die Stadtmenschen schließlich keiner Iiebe zueinander mehr fähig sein werden:

Liebe neigt das stille Antlitz, rafft den starren Rauhreifmantel und geht müde aus der Stadt.II 
Auch ein. Dichter der Deutschen Demokratischen Republik soll hier erwähnt werden, der sich mit dem Problem der Einsamkeit befaßt. Stephan Hermlins "Zwölf Balladen von den großen Städten erschienen im Jahre 1944, als der Dichter noch in der Emigration weilte.

In der *Ballade von der Uberwindung der Einsamkeit in den großen Städtenผ bestätigt Hermlin, daß es wirklich innere Einsamkeit gibt:

Ihr alle, die ihr mit uns in die Großen Städte versanket Und vom Golde des Abends vor Kathedralen berauscht: Wenn ihr vom Gifte tödlicher Einsamkeit tranket, Fühltet ihr einen Schatten...

Der Dichter geht aber noch weiter und findet eine Iösung für die Einsamkeit der Menschen. Und zwar ist es eine Iösung im Sinne der sozialistischen und kommunistischen Weltanschauung. Der Nensch soll sich mit seinen Mitmenschen zu einer Gemeinschaft zusammenschließen, die ein bestimmtes Ziel verfolgt, und als Mitglied dieser großen Gemeinschaft wird er sich bald nicht mehr einsam fühlen.

In einem trostlosen Morgen beginnt unser Herz sich zu härten Mit dem Stahl der Verpflichtung, und wir sind nicht mehr allein. 12 


\section{Kinder $\underline{\text { der }}$ Großstadt}

Auch das Kind hat in der StadtIyrik einen Platz gefunden. Wenn es erwähnt wird, dann aber als benachteiligtes, bedauernswertes Geschöpf der unteren Klassen, niemals aber als fröhliches, in gute Verhältnisse hineingeborenes Kind.

Mehrere Gedichte bringen zum Ausdruck, daß Kinder bei den unteren Klassen unerwüscht sind, da sie die ohnehin armseligen Lebensverhältnisse nur noch erschweren. Georg Trakl schreibt in An die Verstummten , das 1914 erschien, von der Hure, 'die in eisigen Schauern ein totes Kindlein gebärt' .13

In »De Profundus III* erwähnt Johannes Eecher» "Aus verfeuchteten Kellern gebärender Weiber schallende Schreie. «14 während ein anderer Dichter die 'schwangeren Mütter in den Kellern ' bedauert, die einer Geburt ohne Freude entgegensehen.

Gottfried Benn, Arzt und Dichter, berichtet in "Saal der kreißenden Frauen" aus eigener Erfahrung, denn er war Arzt in einem Krankenhaus im Arbeiterviertel Berlins:

Die ärmsten Frauen von Berlin-Dreizehn Kinder in anderthalb Zimmern, Huren, Gefangene, Ausgestoßene-krümen hier ihren Leib und wimmern. 15

Wenn das Kind das Iicht der Welt erblickt hat, wird ihm in der großen Stadt wenig Freude zuteil. Wilhelm Klemms 
Gedicht "Tod in Eerlin" beschreibt das Milieu einer Mietskaserne:

Unter dir werden Heringskartoffeln gegessen,

Einen Ziegelstein weiter brüllt ein Mann mit seiner Frau, Ein Abtritt gurgelt, ein Säugling schreit sich blau.16

Aus Otto zur Lindes Gedicht »Die Stadt«Iäßt sich ersehen, daß Kinder schon früh die Härte des Lebens verspüren muBten:

Da ... scharfe, schnelle Schläge, das Schreien eines gezüchtigten Kindes,

Ha: Schlag und Schrei schneidet wie eine schnellschiebende Säge.17

Auch Rainer Maria Rilke beklagt das Ios der Kinder in "Denn, Herr, die großen Städter. Von Geburt an sind sie zu einem Leben in Armut verurteilt und es ist ihnen versagt, an der Schönheit der Natur teilzunehmen:

Da wachsen Kinder auf an Fensterstufen, die immer in demselben Schatten sind, und wissen nicht, daß draußen Blumen rufen zu einem Tag voli Weite, Glück und Wind,.-und müssen Kind sein und sind traurig Kind. 18

Erich Kästner rührt in Mädchens Klage» an ein anderes Problem: die Frühreife der Stadtjugend, vor allem der. Kinder der unteren Klassen. Kästner hat dieses Gedicht dem Wohnungsamt gewidmet und gibt dadurch seiner Meinung Ausdruck, daß gedrängte, unzureichende Wohnverhältnisse einen großen Teil zu den Problemen der Stadtjugend beitragen: 
Wir wohnen Hinterhaus. Im vierten Stock. Ich kriege schon die ersten Achselhaare. Mein Bruder will mir manchmal untern Rock. Und nächsten Juli bin ich vierzehn Jahre.

Wir haben $b 10 B$ ein. Zimmer, wo wir schlafen, und trotzdem einen fest möblierten Herrn. Der ähnelt sonntags einem schönen Grafen. Und gibt mir Geld. Da tut man manches gern.19

Marleen Vehring schreibt in "Ringel, Rangel, Rose* über die Kinder in den Fabrikstädten des Runrgebiets, denen oft nur ein Fleckchen Asphalt im Hinterhof der Mietskasernen zum Spielen zur Verfügung steht. Aus den Zeilen spricht Bedauern, daß Kinder in solchen Verhältnissen aufwachsen müssen. Die unausgesprochene Anklage der Dichterin ist gegen die Gesellschaft gerichtet:

Da hängt die Wäsche

Da stehen die Mülleimer

$\mathrm{Da}$ ist die Kellertreppe

Da steht ein Auto

$\mathrm{Da}$ scheint keine Sonne

$\mathrm{Da}$ wächst kein Baum

$\mathrm{Da}$ grünt kein $\mathrm{Halm}$

$\mathrm{Da}$ dürfen die Kinder spielen

Die straße ist zu gefährlich 20

Das Thema »Kinder in den großen Städten" ist in den letzten drei Jahriehnten fașt vollständig aus der Stadtlyrik verschwunden. 


\section{V \\ GROBSTADT EERLIN}

Berlin: Berlin: Nun hoch die junge Stirn,

Ins wilde Leben la $\beta$ dich mächtig tragen:

Mit diesem begeisterten Ausruf endet Julius Hart 1882 sein Gedicht "Die. Fahrt nach Berline. Seine Zeilen lassen erkennen, welche Faszinierung die Reichshauptstadt jum die Jahrhundertwende ausübte.

Berlin war bereits $\mathrm{zu}$ einer Millionenstadt angewachsen, die nicht nur der wirtschaftliche, sondern vor allem der kulturelle Mittelpunkt des Landes war. Hier pulsiert das Leben, hier erhält man Inspiration für künstlerisches Schaffen. Is ist verständlich, daß viele Dichter, Schriftsteller und andere Künstler die Stadt zu ihrer Wahlheimat nahmen. Wahrscheinlich ist Berlin, nach Heidelberg, die meist-bedichtete deutsche stadt.

Julius Hart schildert eine Zugfahrt nach. Berlin, die zuerst durch die Kiefernwälder und Heidekraut-bewachsene Landschaft der Mark Brandenburg führt. Aber auch die schönste Landschaft wird bedeutungslos im Vergleich mit dem großen Ereignis der Ankunft in der Hauptstadt selbst:

Die Fenster auf: Dort drüben liegt Berlin: $\dot{E}$ in $\dot{P}$ aradies, ein süßes Kanaan--

Ein Höllenreich und Schatten bleich vermodernd.2 
Ein anderer Dichter des Naturalismus, Richard Dehmel, erinnert sich in»Ausschau bei Nacht» seiner Kindheitsträume, als er sich aus dem einsamen elterlichen Försterhaus in die Großstadt sehnte:

Dort lag Berlin:

Dort lag die Iichtstadt und strahlte: 3

Wie ein Gedicht von Arno Holz zeigt, waren die Dichter des Naturalismus bestrebt, ihre unverschönten Eindrücke widerzugeben, und so entstand die folgende Beschreibung des verschneiten Berlins in "Wintergroßstadtmorgen" :

$$
\text { Durch }
$$

die Friedrichstraße, die

scheublich

gußeisernen Gaslaternen brennen nur halb,

$$
\text { die }
$$

grauen, häßlichen, eintönig toten

$$
\text { Häuserfronten }
$$

zwiedämmern schon, der dunsttrübe Wintermorgen fröstelt 4

In den Jahren vor dem Ersten Weltkrieg war Berlin der Treffpunkt der Künstlerwelt, darunter auch vor allem der Dichter des Expressionismus.

Fritz Hofmann schreibt, daß die 'Stadtlandschaft' der Expressionisten aus Vorstadt, Bahnhöfen und Straßen, aus Cafés, Bordellen und Bars bestand, wo immer der Lebensstrom am schnellsten dahinfloß.5

Kurt Hiller, Gründer des Neuen Clubs in Berlin, forderte eine neue Art der Gedichtschreibung, und zwar: 
Das pathetische Ausschöpfen dessen, was dem entwickeltsten Typus Mensch täglich begegnet, also, ehrliche Formung der tausend kleinen und großen Herrlichkeiten im Erleben des intellektuellen Städters. 6

Dieses Erleben der Stadt auf eine ganz neuartige, intensive Weise--vor allem der stadt Berlin--kommt in den Gedichten der Expressionisten zum Ausdruck. Alfred Iichtenstein sagt in 》Gesänge an Berlin*:

O du Berlin, du bunter Stein, du Biest. Du wirfst mich mit Laternen wie mit Kletten. Ach; wenn man nachts durch deine Iichter fließt Den Weibern nach, den seidenen, den fetten?

Berlin ist ein Erlebnis der Nerven und Sinne, wie ein Dichter dieser Jahre schrieb, und die Eindrücke sind auf verschiedenartige Weise in der Lyrik zum Ausdruck gekommen. Paul Boldt spricht in "Berlink von der Hauptstadt als:

\section{Stahlmasterblühte Stadt aus Stein,} Der Erde weiBe Blume, Berlin ${ }^{8}$

während Ernst Wilhelm Iotz in "Hart stoßen sich die Wändex die Stadt mit verzerrten Kontouren sieht und Menschen und Straßen ein wildes Durcheinander formen.

Hart stoßen sich die Wände in den Straßen, Vom Licht gezerrt, das auf das Pflaster keucht, Und Kaffeehäuser schweben im Geleucht

Der Scheiben, hoch gefüllt mit wiehernden Grimassen.9 
Berlin war aber auch der politische Mittelpunkt des Reiches, und nach dem Zusammenbruch der Ronarchie am Ende des Ersten Weltkriegs wurde es die 'Brutstätte' der Iinksorientierten Bewegungen. Ein Gedicht von Rudolf Leonhard aus dem Jahre 1920.mit dem TiteI "Von Stadt zu Stadt mag als Prototyp dieser Art Berlin-Gedichte dienen:

Geh' durch Berlin. Nachts, wenn die trüben Iichter auf am Asphalt genäßten Schmutze kleben, die Wagen halten, Ubermüde eben nach Hause fallen, von der Arbeit dichter bedrängt und blaß... • Und die Stadt

schreit aufgewühlt nach Revolutionen.10

Auch nach dem Zweiten Weltkrieg stand Berlin wieder im.Blickfeld politischen Geschehens. Die Teilung der stadt in einen Ost- und Westsektor im. Jahre 1949, sowie die Errichtung der Mauer 1961 spiegeln sich in der Lyrik wider.

Günter Kunert, Dichter der DDR, stellt Betrachtungen darüber an in "Wie mir heute meine stadt erschien*
da ist eine Stadt, von der man
nichts weiß, als
daß durch sie Grenzen gehen von zwei großen Reichen, von Krieg und Frieden, und als daß in ihr kein. Iaut tönt, wenn Nebel steigt.11

Freimut Arlt sieht die Teilung der Stadt aus der Perspektive eines Westdeutschen. Sein Gedicht "Hauptstadt der DDR spielt auf die Erleichterung der Besuchsmöglichkeiten zwischen 0st- und Westberlin an, die 1968 erzielt 
wurde, und derironische Ton zeigt des Dichters eigene Ansicht über die politischen Abmachungen.

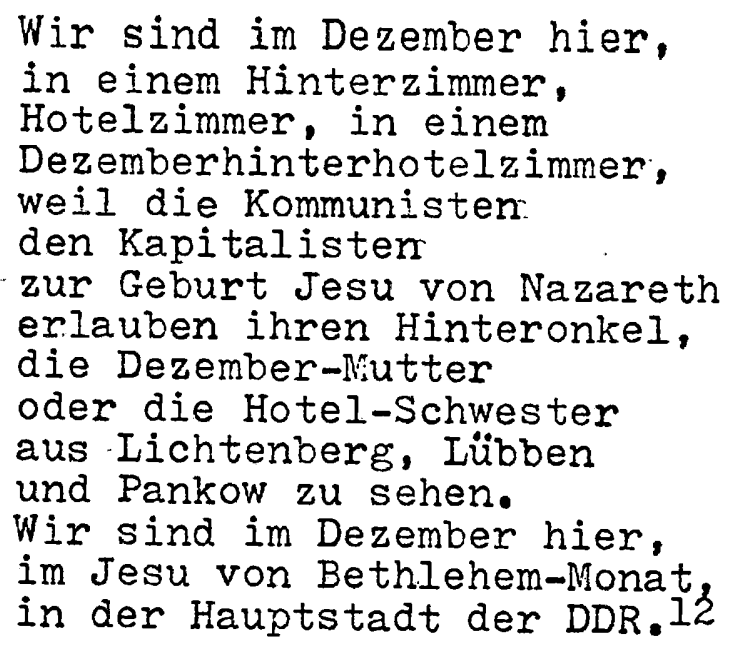

Niemand kann voraussehen, wie sich die politische Lage Berlins weiterhin entwickeln wird. Gerald Bisinger gibt allerdings in seiner 1971 erschienenen $\gg$ Ballade-Cde Berlin-Berlin der Meinung Ausdruck, daß an eine Einigung Berlins, und damit des Westens und Ostens, nicht zu denken sei:

Mauer die weltberühmte die Minen- und Stacheldraht ist technisch perfektioniert schärfer das Urenze im Westteil der $\dot{\text { stadt }}$

von Strukturen West-Ost die anzugleichen sich scheinen ein gefährlicher Wunschtraum im Westen die Einheitssuppe sie wird nicht gekocht.13 


\section{VI}

\section{DIE STADT IM KRIEG}

Seit Menschengedenken gibt es Kriege. Uber Städtefehden in vergangenen Jahrhunderten wird in alten Chroniken berichtet, und oft sind die schilderungen in Versform geschrieben wie die "Burgundische Hystorie des Hans Erhard Düsch». Dieser berichtet über einen Feldzug, während der Burgundischen Kriege 1476-77:

Zu rosz zu fusz, wie man ir darff,

Und wie man si erwunschen kund.

Die von Lybeck ouch gar scharff

Koment da hin der selben stund.

Mit groszer macht und wol gerust

Augspurg, die dahinden nie

Verleib und die ouch nie verwust

Des glich die statt von Nuremberg

Sant ouch ir volck vast rustig darl

Zweihundert Jahre später schilderte Andreas Gryphius in "Threnen des Vatterlandes Anno 1636* die Zerstörung einer Stadt im Dreißigjährigen Krieg:

Die türme stehn in glutt

die Kirch ist umbgekehret.

Das Rahthaus ligt im graus

die starcken sind zerhawn

hier durch die schantz undt stadt

rint alzeit frisches blutt. 2 
In den Kriegen der folgenden Jahrhunderte erlitten die deutschen Städte verhältnismäßig wenig Schaden, was bis zu einem gewissen Grade mit der Art der Kriegsführung zusammenhängt.

Obwohl das Thema $>$ Krieg" nach 1945 in einer Anzahl deutscher Gedichte erscheint, befaßt sich doch kaum eines mit der Auswirkung des Krieges auf die Städte.

Aus Statistiken geht hervor, daß über dreißig Prozent des städtischen Wohnraums im Zweiten Weltkrieg zerstört wurde, und doch wurde die katastrophale Verwüstung von den

Lyrikern vollständig ignoriert. Dies ist ein Phänomen, das in so mancher Iiteraturkritik diskutiert wird。

Auch Peter Hamm äußert sich in Aussichten. Junge Lyriker des deutschen Sprachraums zu diesem unerwarteten Stillschweigen der deutschen Lyriker nach dem Krieg. Er sagt, daß die Dichter. 'der Katastrophe den Rücken kehrten und Trost beim Zeitlosen, bei der Natur und dem Alt-Wahren suchten', und fährt dann fort:

Wo das Grauen des Kriegs überhaupt ins Gedicht geriet, wurde es meistens ästethisiert oder mythifiziert. Im übrigen drückte man sich, die Folgen des Krieges und die Zerstörung in Stadt und Land im Gedicht darzustellen.3

Was auch die Gründe sein mögen, es steht fest, daß sich in der westdeutschen Lyrik nur sehr wenige Gedichte mit der Kriegsauswirkung in den Städten befassen. 
Diese Feststellung gilt jedoch nicht für die Iyrik der $D D R$, deren Dichter sich eingehend mit diesem Thema beschäftigt haben. Alle nachfolgend angeführten Gedichte stammen daher ausschlieBlich von Lyrikern dieses Landes. Michael Franz beschreibt in "Erster Mai 1946 die Verwüstungen in Berlin:

$$
\begin{aligned}
& \text { Wir laufen durch } \\
& \text { tote Straßen, } \\
& \text { amputierte Natur } \\
& \text { im Tiergarten, } \\
& \text { die Felaherrn } \\
& \text { liegen im Dreck } \\
& \text { (spät genug) } 4
\end{aligned}
$$

Wie aus diesem und auch dem folgenden Gedicht hervorgeht, ist das Thema 'Krieg' häufig mit einer politischen Botschaft verbunden. In "Dresden* beschreibt Max Oswin Schubert die Zerstörung dieser Stadt durch Fliegerangriffe westlicher Mächte. Dann betont er den Wiederaufbau im sozialistischen Stat:

Beseitigt sind die nackten Reste des Grauens. Und unter dem Mond trauern nicht immer erneut diese verkrüppelten stümpfe. Die Türme haben wieder vergoldete Stirnen, und schöner reicht nun ihr Schmuck hinüber zum Strom, sonnenbeladen, und Glanz spielt mit Glänzen. sind wieder die Maße der Ordnung erkennbar.5

Johannes Becher zeigt den Krieg aus einer anderen Perspektive in "Fliegerbomben prasselten . Er schildert das 
Entsetzen der Stadtbewohner in den Iuftschutzkellern, die dem Holocaust hilflos ausgesetzt waren.

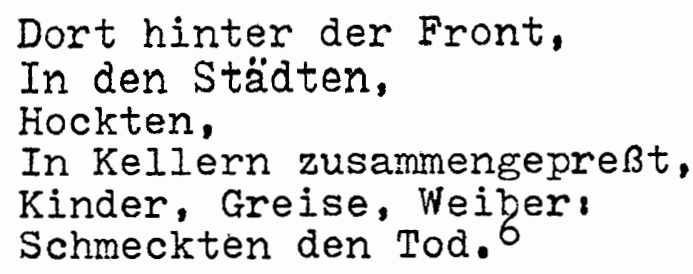

Auch Bertolt Brecht, der Deutschland bereits 1933 verlassen hatte, schreibt über die Zerstörung deutscher städte und wirft in "Rückkehr» die Frage auf,

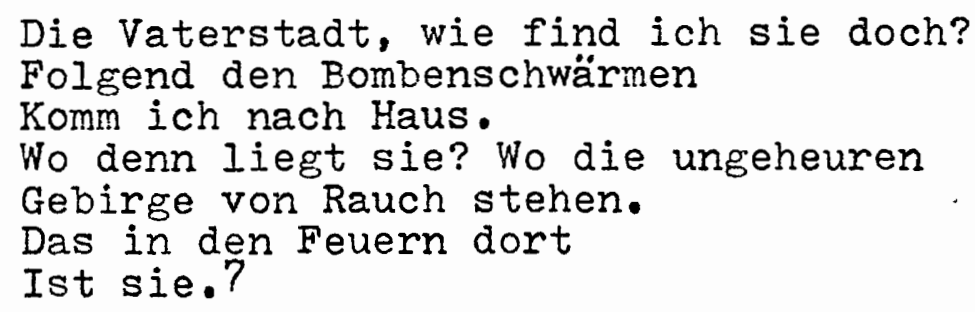

In "Als unsere Städte in Schutt lagen" weist Bertolt Brecht auf den Wiederaufbeu der Städte hin, der nur dann einen Sinn hat, wenn damit gleichzeitig eine Anderung der bisherigen Weltanschauung verbunden ist:

Als unsere Städte in schutt lagen Verwüstet durch den Krieg des Schlächters Haben wir begonnen, sie wieder aufzubauen In der Kälte, im Hunger, in der Schwäche.

Dann machten wir für diese unsere Kinder In den Schulen Platz und säuberten die Schulen Und reinigten das Wissen der Jahrhunderte Vom alten Schmutz, daß es gut für sie sei. 8 
SATIRE, IRONIE UND HUMOR IN STADTGEDICHTEN

In den zwanziger Jahren, als die Schrecken des Ersten Weltkriegs Iangsam in Vergessenheit gerieten und ein neuer Lebenstaumel sich der Menschen zu bemächtigen schien, entstand eine neue Art von Stadtgedichten, die für diese Zeit typisch sind und weder vorher noch später eine Parallele haben. Die Stadt, und besonders der Stadtmensch, werden auf eine Weise dargestellt, die in ihren Schattierungen zwischen humoristisch und satirisch schwankt.

Albert Sörgel bemerkt dazu in Dichtung und Dichter der Zeit:

Neben den Stadtgedichten von Arno Holz, Oskar Ioerke, Däubler, zur Iinde und anderen entwickelte sich eine neue enthusiastische Großstadtlyrik, die ihren Ort im Kabarett fand. Erich Kästner, Joachim Ringelnatz, Martin Kessel, Walter Mehring neigten zu Witz,. Spott und Satire und griffen die Tabus der Gesellschaft auf, zum Beispiel Sex, Politik and andere. 1

Viele der humoristischen Gedichte wurden vom Kabarett aufgegriffen, so zum Beispiel Walter Mehrings 1919 entstandene Verse "Die Iinden lang«. Der Dichter charakterisiert darin die obere Schicht der Berliner Bevölkerung, 
die sich schnell von den Schrecken des Kriegs erholte und sich in Vergnügungen aller Art stürzte:

\author{
Die Iinden lang: Galopp: Galopp: \\ Zu Fuß, zu Pferd, zu zweit! \\ Mit der Uhr in der Hand, mit'm Hut auf'm Kopf, \\ Keine Zeit: Keine Zeit! Keine Zeit!2
}

Der leichte und.witzige Ton täuscht aber nicht darüber hinweg, daß die meisten Gedichte eine tiefe Wahrheit enthalten und die Zustände in der Stadt sowie die Schwächen des Großstadtmenschen bloßstellen.

Erich Weinerts "Republikanischer Abend" entstand im Dezember 1921, zur Zeit der Weimarer Republik. Hier schildert er auf amüsante weise den abendichen Bummel wohIhabender Damen durch den Park einer Stadt. Doch weist der Dichter auch darauf hin, daß die schweren Folgen und die Leidtragenden des großen Krieges von der Gesellschaft nur allzu schnell vergessen werden.

Im Parke schweift Frau Rechnungsrat

Mit einem Schwanz von Pensionetten;

Die Mädels wandeln wie auf Draht

Und träumen heimlich von Kadetten.

Und plötzlich singt der ganze Schwanz,

Daß man nicht ohne hohe wönne

Der Abendsonne ihren Glanz

Und ohne lust betrachten könne.

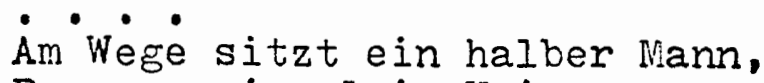

Der war einmal im Krieg gewesen;

vian schaut inn mitbeleidigt an

Von wegen seiner Beinprothesen. 3

Im Jahre 1928 erschien ein Gedicht von Erich Kästner 
mit dem Titel "Chor der Fräuleinsณ. Zu dieser Zeit,

als Arbeitslosigkeit und Inflation in Deutschland herrschten, weist der Dichter ironisch auf die Zustände im Lande hint

Wir hämmern auf der Schreibmaschine. Das ist genau, als spielten wir Klavier. Wer Geld besitzt, braucht keines zu verdienen. Wir haben, keins, drum hämmern wir. 4

In dem gleichen halb witzigen, halb ironischen Ton rührt Erich Kästner auch an ein anderes, weitverbreitetes Problem: die innere Einsamkeit des Großstadtmenschen. In "Sozusagen in der Fremder sagt der Dichter, daß sich der Mensch auch in der größten Menge unendlich allein und verlassen vorkommen kann:

Er saß in der großen stadt Berlin an einem kleinen Tisch. Die Stadt war groß, auch ohne ihn. Er war nicht nötig, wie es schien. Und rund um ihn war Plüsch. Er strich das weiße Tischtuch glatt. Und blickte in das Glas. Fast hatte er das Ieben satt. Was wollte er in dieser stadt, in der er einsam saß?5

Christian Morgenstern macht sich über die Mischung von Wirtschaft und Politik Iustig. Er sagt in 》Aus der Vorstadta, daß es wohlbekannt ist, wer die Finanzen einer Stadt wirklich in der Hand hat, 
Ich bin eine neue Straße noch ohne Haus, O Graus. Ich bin eine neue Straße, und sehe komisch aus.

…

Die Herren Aktionäre,

die haben mir schon vertraut.

Es währt nicht lange, auf Ehre,

so werd' ich angebaut.6

Vielleicht sollte man auch das Gedicht eines bisher noch unbekannten jungen Dichters zu der Kategorie der ironischen Stadtgedichte zählen. Hermann Körner wählte für sein 1970 erschienenes Gedicht den Titel "harmonische. Er macht: sich darin über die Selbstzufriedenheit der Stadtbewohner lustig, die in neuem Wohlstand schwelgen und ganz materialistisch eingestellt sind. Sie scheinen zu vergessen, daß Reichtum und Sicherheit schnell vergängliche Dinge sind:

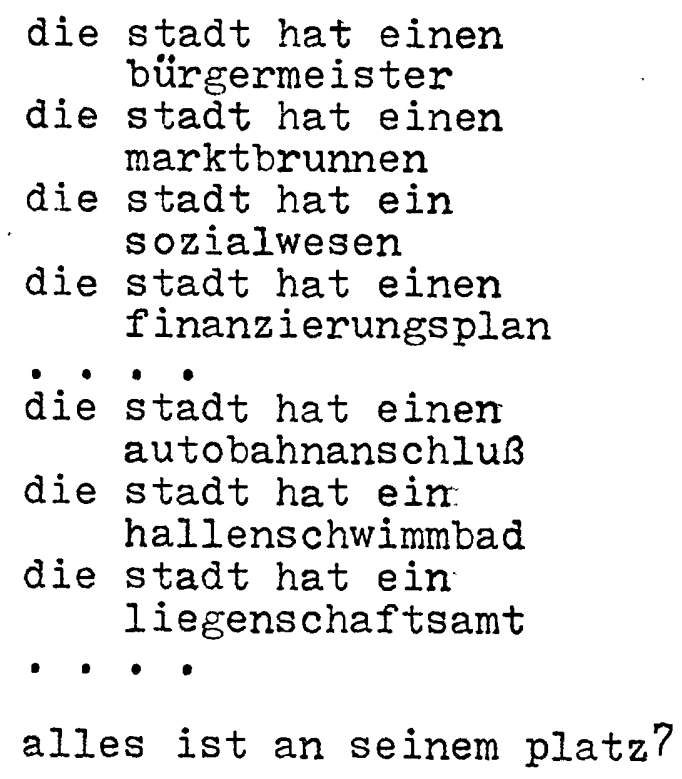




\section{VIII}

\section{DIE IIEBE ZUR STADT}

Schon immer vermochte die geliebte Heimatstadt oder das malerisch gelegene Städtchen im Glanz der Sonne oder beim Licht des Mondes das Herz des Dichters zu entzücken und ihn $\mathrm{zu}$ Versen $\mathrm{zu}$ inspirieren.

Man denke an Friedrich Hölderlins Hochgesang auf Heidelberg:

Lange lieb' ich dich schon, möchte dich, mir zur Lust, Niutter nennen, und dir schenken ein kunstIos Iied, Du, der Vaterlandsstädte Iändlichschönste, so viel ich sah.I

Auch Theodor Storms Heimatstadt Hamsun, mag sie auch noch so grau und in Nebel verhüllt am Strande liegen, ist eine geliebte Stadt, wie des Dichters Zeilen bekunden:

Doch hängt mein ganzes Herz an dir, du graue Stadt am Meer; der Jugend Zauber für und für ruht lächelnd doch auf dir, auf dir, du graue stadt am Meer. 2

Jedoch waren all diese schönen und geliebten Städte des achtzehnten und neunzehnten Jahrhunderts, besonders nach unserem heutigen Begriff, nur kleine und beinahe ländliche städte. Gibt es denn, so fragt man sich, 
auch Dichter, die die großen, grauen, lauten Städte als liebenswert empinden?

Ernst Blass, ein Dichter des Frühexpressionismus, war von der Stimmung in den nächtlichen Straßen, den Parks, Cafés, von dem ganzen flutenden Verkehr und Lichtermeer der großen Stadt bezaubert. Er beschreibt das Berliner Milieu, das für ihn besondere Reize hatte, mit Versen wie:

Iaternen schlummern süß und schneebestaubt

In Straßen, die sich weiß wie Küsse dehnen

Da unten rollen meine Omnibusse

Stefan George, der das Thema der Stadt kaum in seinen Gedichten behandelt, verfaßte jedoch ein Loblied auf die bayrische Hauptstadt München:

Wauern wo geister noch zu wandern wagen, Boden, vom doppelgift noch nicht verseucht: Du stadt von volk und jugend: heimat deucht uns erst wo Unsere Frauen türme ragen. 3

Um Stefan Georges »Gedicht an München verstehen zu können, mag man Albert Sörgels Erklärung dazu lesen

Mit dem 'doppelgift' meinte Stefan George das Elend der großstädtischen Zivilisation, das er in Berlin, Paris und Iondon kennengelernt hatte, und die materialistische und anti-idealistische Kunstauffassung der »Moderner, also den Naturalismus. 3

Verschiedene Dichter sind der Meinung, daß weder eine idyllische ländliche Umgebung noch die Natur im allgemeinen der ewig-faszinierenden Stadt gleichkommen können . Armin T. Wegner schrieb 1915 den »Gesang von den Straßen der Stadt 
und stellt darin Vergleiche an zwischen der Stadt und Natur, wobei die Großstadt der unbestrittene Sieger ist:

Euch will ich singen, breitbuchtige Straßen, wildüberwühlte Plätze, Blutrinnende Adern der unendlichen Stadt. Wo brauste der Sturm mir stärker, denn in euren zwischen euren Häusern, Schluchten, Alle Qualen aus meiner Seele lösend. 4

In Gerritt Engelkes "Heimkehr*, erschienen im Oktober 1917, sind ähnliche Gefühle ausgedrückt. Das Dorf und Ackerland erscheinen dem Dichter langweilig und trübselig im Vergleich mit den Reizen der großen Stadt, wo 'Einsamkeit gegen Gemeinschaft' getauscht werden kanns

Horch hoch:

Die Telegraphendrähte brummen, summen mit:

Ein Licht blüht auf im Straßenkot,

Ein zweites, ein drittes im Dämmerrot;

Und plötzlich:

Iichterkreisend, lichterdunstig loht

Gehäufter Himmel über Mauern schwer!

Die Luft durchschüttert Atemstoß-Geschnauf;

Dich fassend schwillt herauf,

Der große Qualm- und Räderton:

Nun hat die Stadt dich angerührt. 5

Auch die Arbeiterdichter singen das Loblied der der großen Stadt. Aber sie übersehen nicht, wie manch andere Dichter, die Schattenseiten der Stadt, die soziale Not und die Klassenunterschiede. Johannes Becher verkündet in "De Profundis III«, daß die großen Städte der Ausgangspunkt 
zur Iösung dieser Probleme sein sollen:

Und doch--: singe mein trunkenstes Loblied auf euch ihr großen,ihr rauschenden Städte:

Von euch verdorben. In euch verirrt. Von euch verführt. Doch sterbend vom Schein himmlischen Iichtes berührt. . Denn piötzlich schrillen empor Sturmglocken und Pfeifen: 6

Eine tiefe Liebe zu seiner Heimatstadt Hamburg tritt in Wolfgang Borcherts Gedichten zutage. Sie entstanden in den frühen vierziger Jahren, als Hamburg bereits schwer unter den Folgen des Krieges gelitten hatte. Der Dichter liebt und akzeptiert seine Heimatstadt ohne Reservationen, wie "Im Hamburg" zu lesen ist:

In Hamburg kann die Nacht nicht süße Melodien summen mit Nachtigallentönen, sie weiß, daß uns das Iied der Schiffsirenen die aus dem Hafen stadtwärts brummen, genau so selig macht.?

Für Borchert ist die große Heimatstadt Hamburg nicht nur 'Göttin' und 'Hure', sondern sie ist zugleich auch 'Mutter' und gewährt dem Heimkehrenden Zuflucht und Geborgenheit;:- wie der Dichter in $\gg$ Großstadt sagt,

und wenn wir leer und müde sind, nimmt sie uns in den grauen Schoß-und ewig orgelt über uns der wind: 8

In den Stadtgedichten der Deutschen Demokratischen Republik kommt die Liebe zur Heimatstadt oder der Stolz auf die fortschrittliche stadt manchmal in überschwänglichem 
Ton zum Ausdruck. Rose Nyland zählt in ihrem Gedicht "Die Stadt all die ihr wundervoll erscheinenden Dinge auf, die es in ihrer Heimatstadt zu sehen gibt:

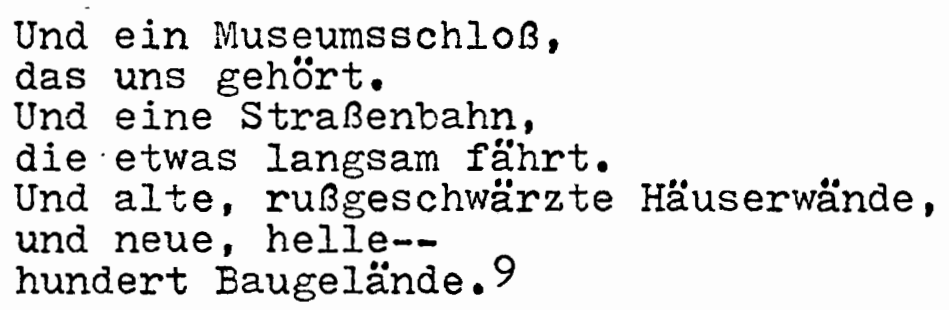

Dieses Gedicht ist wie die meisten DDR-Gedichte im Sinne des sozialen Realismus geschrieben und betont Aufbau und Fortschritt. Vor allem wird aber auf die Zusammenarbeit der Menschen hingewiesen und die Aussicht auf eine bessere Zukunft, wie aus der letzten Strophe hervorgeht,

Wir haben viele, viele Arbeitshände. Ein großes Herz, das nie den Mut verliert. Wir haben Träume, und wir haben Iieder. Und manches ist noch gar nicht registriert. 9 
MYTHISIERUNG DER STADT

Die Darstellung der großen Stadt als ein von übernatürlichen, unheimlichen Mächten Beseeltes oder Verfolgtes ist in der deutschen Lyrik fast ausschIießlich auf die Epoche des Expressionismus beschränkt.. Diese überirdischen Mächte--oder in manchen Fällen auch die Stadt selbst--nehmen die Form verschiedener Gestalten wie Dämonen, Götter, Riesen oder Gespenster an.

Iiteraturkritiker sind sich darüber einig, daß Georg Heym als erster deutscher Dichter die Stadt mythisierte, wenn er in seinen Gedichten von unheilbringenden Dämonen sprach. Jedoch ist keineswegs klar, inwieweit Heym von dem französischen Dichter Arthur Rimbaud beeinfluBt worden war. Dieser beschrieb Ende des neunzehnten Jahrhunderts die Stadt als 'stinkendes Geschwür' und sprach von ihrer 'verruchten Schönhèt:.

Heym selbst hat niemals eine direkte Begründung für die Verfluchung der Städte in seinen Gedichten gegeben. Jedoch enthält vielleicht eine Aussage Paul Zechs, der mit Georg Heym eng befreundet war, eine mögliche.Erklärung:

Er durchschaute die großen Städte mit ihren überdimensionalen Maschinen und versklavtem 
Proletariat, mit ihren geistigen, wirtschaftlichen und politischen Katastrophen, mit ihrem Hindrängen zum Krieg und ihren faden Surrogaten. I

Einige Literaturkritiker sind der Ansicht, daß Heyms vorausgesagter Untergang der Stadt nicht nur auf die Stadt selbst beschränkt ist, sondern daß man darin ein Zeichen für das Ende der Welt und der ganzen Menschheit erblicken sollte. Auf jeden Fall steht fest, daß sich Heyms Einfluß in den Gedichten vieler anderer deutscher Iyriker dieser Zeit bemerkbar machte.

Die meistdiskutierten Stadtgedichte Heyms sind $" D e r$ Gott der Stadtk und "Die Dämonen der Städtek, das hier teilweise zitiert ist. Die Stadt fällt übernatürlichen Mächten, den Dämonen, zum Opfer:

Sie wandern durch die Nacht der Städte hin, Die schwarz sich decken unter ihrem Fuß. Wie Schifferbärte stehen um ihr Kinn Die Wolken schwarz vom Rauch und Kohlenruß.

- $\cdot$ -

Sie lehnen schwer auf einer Brückenwand

Und stecken ihre Hände in den Schwarm

Der Menschen aus, wie Faune, die am Rand

Der Sümpfe bohren in den Schlamm den Arm. 2

Egbert Krispyn schreibt in Georg Heym. A reluctant Rebel, daß die Stadtmenschen in Heyms Gedichten ihre Individualität verlieren und als 'Schwarm' bezeichnet werden. "The reference to the teeming millions serves Heym to reduce humanity to an anonymous, amorphous mass. 3

Auszüge aus Stadtgedichten verschiedener Lyriker des 
Expressionismus lassen den Einfluß Georg Heyms erkennen. Jakob van Hoddis schreibt:

Und auf den Straßen tönt der Schrei der Riesen Durch Kinderlärmen und der Sturmgesang

Der Telegraphendrähte. Horch: Er brülit 4

In "Die Zeichen* schildert Alfred Iichtenstein die Symptome einer sterbenden Stadt, die von einer ungenannten feindlichen Macht zerstört wird:
Die Straße stirbt $a b$.
Die sinkende Sonne sticht.
Die luft wird knapp.
Das Herz zerbricht.5

In der Art Georg Heyms personifiziert Karl Bröger in seinem "Zweiten Sonette den Hunger, der als zerstörende Macht die Stadt betritt und überwältigtı

Gebietend tritt der Hunger in die Stadt Und streift ihr $a b$ die erzgegoßne Kette, Daran die Arbeit sie gehalten hat. 6

Paul Zech benützt in »Stadt in Eisen" ein Motiv aus der Welt der Eisenindustrie--die Stahlscheren--die den Menschen der Fabrikstädte Vernichtung bringen.

Da packen dich der Türme Stahlscheren schon und pressen Atmung, Denken und Gesicht.

Das Gas der Armut eitert durch dein Blut und sticht

Im Fleisch wie Rudel tausendfüBiger Gewürme.?

Walter Steinbach malt in seinem Gedicht "In mitternächtigen Städten« eine Szene des Grauens. Der 'Götze', 
dem die Stadtmenschen dienen, bricht los und zerstört sie alle:

Mit seinen Pranken streichelt er die Türme Der goldenen Dome und der Prunkpaläste. In seinem Atem wehen wilde Stürme.

Er mästet sich sein Wanst bei jedem Feste.

Die Menschen aber wissen's nicht, Daß er sie niederwirft trostlos zum Beten, Und es erlischt des Aufruhrs rotes Licht Vom Fieberschrei in mitternächtigen Städten 8

Mit dem Ende der expressionistischen Literaturströmung Anfang der zwanziger Jahre nahm auch diese besondere Art der Stadtlyrik, die Mythisierung der Stadt, ihren Ausklang und wurde in der späteren stadtdichtung nie wieder aufgegriffen. 


\section{$\mathrm{X}$ \\ METAPHERN UND FARBEN \\ IN GEDICHTEN UBER DIE STADT}

Wer das Kommen und Gehen der Menschenmassen, den ständigen Fluß des Verkehrs, das An- und Abschwellen des Straßenlärms einer Großstadt kennt, wird verstehen können, daß ein Vergleich mit dem nimmer-endenden Fluß des Wassers naheliegt.

In einer großen Anzahl von Stadtgedichten lassen sich solche Vergleiche finden. Dabei handelt es sich um alle möglichen Formen des Wassers wie Meer, Ozean, Flut, Fluß und See, oder eng damit verbundene Begriffe wie Strand, Schiff, Welle, Seevogel und ähnliche. Der Vorstellungskraft der Dichter ist keine Grenzen gesetzt.

Wie Heinz Rölleke erwähnt, tritt der Begriff des 'océan de l'immonde cité' bereits in Charles Baudelaires Gedichten auf. I In der deutschen Lyrik ist die WasserMetapher an keine Iiteraturströmung gebunden. Sie ist bereits in den Stadtgedichten vor der Jahrhundertwende sowie in der Iyrik der Gegenwart zu finden.

Die hier angeführten Auszüge aus Stadtgedichten sollen die Vielfalt der Vergleiche zeigen, deren sich die deutschen Dichter bedienten. Die Reihe der Beispiele könnte beliebig verlängert werden. 
Julius Hart, Dichter des Naturalismus, schildert die Stadt Berlin in seinem gleichnamigen Gedicht:

Endlos ausbreitest du, dem grauen Ozean gleich, den Riesenleib.

Erzittert nicht die Luft vom dumpfen Toben

Des Neeres, das in deinen Schlünden bricht

Und wühlt und brandet, wie vom Sturm durchstoben,

Und donnernd tausend Schiffe zusammenschleudert?2

Auch Armin Wegner vergleicht die Reichshauptstadt in »Gesang von den Straßen der Stadt mit einem wildbewegten Meer:

In ihrer Woge treibe ich dahin, stoßend und wieder

Ein rollender stein in der Flut 3

gestoßen,

Ernst Stadler benützt das Motiv des Schiffes in seinen Gedichten »Dämmerung in der Stadt» und 》Gang in der Nacht« . Es ist aber nicht ein großes, stolzes Schiff auf dem Meer, sondern nur der 'Rumpf' eines Schiffes. mit dem er die grauen Häuser der Stadt vergleicht:

Die Häuser sind im Grau, durch das die ersten Iichter. branden wie Rümpfe großer Schiffe, die im Meer die Nachtsignale hissen. 4

Im Schreiten

springen die Häuser aus dem Schatten vor Wie Rümpfe wilder Schiffe auf entferntem Meer. 5

In "Straßer spricht Bruno Wille von dem dahinfließenden lauten Straßenverkehr: 
branden die rasselnden Wagen, die Menschen wie Wellen in klippiger Meeresbucht ${ }^{6}$

während Luis Fürnberg in "Abend" die Geräusche der Stadt schildert, die er auf einem abendichen Gang wahrnimmt:

Wenn der Abend durch die große Stadt geht, ist's, als hielt ich eine Muschel an mein $\mathrm{Chr}$ und ich lausch' dem Rauschen, das vom Meere weht.?

Iwan Goll vergleicht in "Die Automammuts" die Stadtmenschen mit dem 'Gischt' des Meeres, der durch die Straßen schäumt.8

Auch in Georg Heyms Stadtgedichten finden sich Vergleiche mit dem Meer. Er spricht vom 'Riesensteinmeer' Berlin und vom 'Ebben der Weltstadt'. Heinz Rölleke schrèibt über den Gebrauch dieser Metaphern in Heyms Gedichten:

Gestalt und Wesen des Meeres und der Stadt sind für Georg Heym übertragbar und einander unzertrennbar zugeordnet. Größe und Weite der Städte sind die Ausdehnung, die Unermesslichkeit des Meeres; das Großstadtleben ist ein ununterscheidhares Gewoge. Wie ein Meer, 'unermesslich, rücksichtslos und unbarmherzig alles überwallend' erstreckt sich die Stadt in alle Richtungen. 9

Oskar Loerke, dessen "Blauer Abend in Berlin* 1911 entstand, also fast zur gleichen Zeit wie Heyms Gedichte, malt dagegen ein friedliches Bild vom Leben in der GroBstadt. Das Schicksal des Stadtmenschen wird gütig und sicher von der 'großen Wellenhand' gelenkt. 
Im Dünen, Kommen, Gehen, Gleiten, Ziehen. Die Menschen sind wie grober, bunter Sand

Im linden Spiel der großen Wellenhand. I0

Auch Dichter der neueren Zeit bedienen sich der MeerMetapher. Hans Leifhelm, der über die Industriestädte schreibt, schildert in "Industriesonntag" eine Ruhrlandschaft, wo am Sonntag wie Alltag die Arbeit weitergeht:

Rauch wühlt wie sturmzerfleischte Seevögel über Land, Schlacken liegen verklimmend wie Wracks am dampfenden Strand.

Sturm heult in tausend Sirenen, schwarz wogt der

Wellen von Menschen branden am steinernen Wall. 11 Dül,

Es kommen auch noch andere Metaphern in der deutschen Stadtlyrik vor, jedoch findet die 'Wasser-Metapher' bei weitem die häufigste Anwendung.

Fast alle Farben, die zur Beschreibung der Großstadt dienen, gehören zu den düsteren oder fahlen Farbschattierungen. Mietshäuser sind grau, und die Wohnungen darin sind dunkel. Der Straßenasphalt ist schwarz und die Straßen sind von schmutzigem Grau. Wenn sich der Abend über die Stadt senkt, werden blaue, graue oder dunkle Schatten bemerkbar, während Lampen und Laternen einen trüben, weißen oder gelben Schein ausstrahlen.

Der Himmel ist oft verhangen, und auch die Morgendämmerung zieht grau oder fahl über dem Häusermeer auf. Zwar wird $a b$ und $z u$ ein rotes Licht erwähnt, aber es ist nicht als lebbafter Farbkleks, sondern als Symbol für das Nachtleben aufzufassen. 
Es gibt kaum ein Gedicht, das die große Stadt in hellen, freundichen Farben darstellt. Auch Wolfgang Borcherts 》Graurotgrünes Großstadtlied" stellt den lebhaften Farben grün und rot immer wieder das düstere Grau gegenüber,

Rote Münder, die aus grauen Schatten glühn, girren einen süßen Schwindel. Und der Mond grinst goldiggrün durch das Nebelbündel.

Graue Straßen, rote Dächer, mittendrin mal grün ein Iicht. Heimwärts gröhlt ein später Zecher mit verknittertem Gesicht.

Grauer Stein und rotes Blut-morgen früh ist alles gut. Morgen weht ein grünes Blatt über einer grauen Stadt.12

Axel Schulze, ein Dichter der Gegenwart, reiht verschiedene Farbeindrücke über die Stadt aneinander, doch sind. auch in diesem Gedicht, das den Titel „Farben der Städte» trägt, die dunkleren Töne vorherrschend,

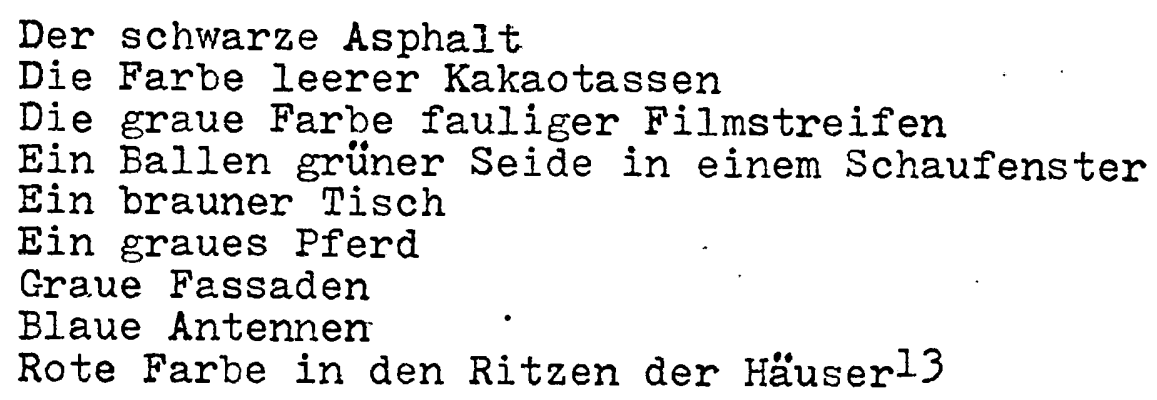

In den meisten Stadtgedichten haben Farben eine beschreibende Funktion. Bei einigen Dichtern des Expressionismus nehmen Farben jedoch eine besondere, tiefere Eedeutung an, vor allem bei Georg Heym und Georg Trakl. 
Kurt Mautz bemerkt dazu in Mythologie und Gesellschaft im Expressionismus, daß die Farben bei diesen beiden Dichtern losgelöst sind von dem sinnlich wahrgenommenen Gegenstand, und daß jede der genannten Farben eine bestimmte Funktion im Gedicht zu erfüllen hat. Er sagt weiterhin, daß Heym und Trakl den Grundtendenzen der Farbensprache' von Arthur Rimbaud folgten und daraus ihre eigene Retaphorik entwickelten. 14

Im Gegensatz zur westdeutschen Stadtdichtung sind in der Stadtlyrik der Deutschen Demokratischen Republik die bunten, hellen, und somit optimistischen Farbtöne häufig vertreten. Besonders die rote Farbe wird immer wieder erwähnt:

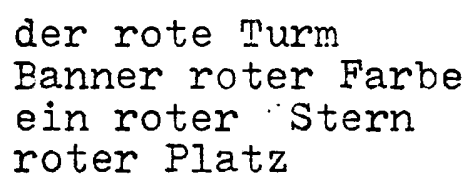

Es ist zu vermuten, daß diese Farbe in der DDR-Lyrik eine symbolische Bedeutung hat. 


\section{ZUSAMMENFASSUNG}

Gegen Ende des neunzehnten Jahrhunderts erscheint 'die Stadt' zum ersten mal als selbständiges Thema in der deutschen Lyrik. Die große Anzahl an Stadtgedichten, die seit diesem Zeitpunkt geschrieben wurden, läßt erkennen, daß das bewegte Leben einer Großstadt und der Stadtmensch selbst faszinierende Themen für den Dichter sind.

Die geschichtliche Entwicklung der Stadt vom Iändlichen Städtchen des Mittelalters bis zur modernen Metropolis kann anhand von Urkunden und Chroniken und seit dem siebzehnten Jahrhundert auch anhand von Statistiken verfolgt werden.

Im Zeitalter der industriellen Revolution vergrößerten sich viele Städte ungewöhnlich rasch, was zum Bau von Mietskasernen und ganzer Arbeiterwohnviertel führte. Die damit verbundenen sozialen MiBstände sind in den ersten deutschen Stadtgedichten vor der Jahrhundertwende zum Ausdruck gebracht.

In späteren Jahrzehnten, besonders während des Expressionismus, erscheint ein weit größeres Spektrum des Großstadtlebens in der deutschen Stadtdichtung. $\mathrm{Zu}$ den Aspekten, die besonders oft in der Großstadtlyrik 
erscheinen, gehören die Verschmutzung der Städte, gedrängte WohnverhäItnisse, Klassenunterschiede und die Vereinsamung des Stadtmenschen, um nur einige zu nennen.

Die Stadt wird von den deutschen Dichtern oft auf sehr verschiedene, widersprechende Weise dargestellt. Vor etwa dreihundert Jahren bezeichnete Herder die Städte seiner Zeit als 'Werkstätten des Fleißes, Nuster bürgerlicher Weisheit und gleichsam stehende Heerlager der Kultur'.1

Bertolt Brecht dagegen sagt von den Städten unserer Zeit:

Unter ihnen sind Gossen

In ihnen ist nichts, und über ihnen ist Rauch. Wir waren darinnen. Wir haben nichts genossen. Wir vergingen rasch. Und langsam vergehen sie auch.2

Die Darstellungsweise der Stadt hängt $z u$ einem großen Teil von den persönlichen Empfindungen und Eindrücken eines Dichters $a b$, und auch seine Erziehung, Bildung, und andere Faktoren scheinen dabei eine Rolle zu spielen. Für manche Dichter ist die Großstadt der Mittelpunkt des pulsierenden Lebens, wo er Anregung und Inspiration erhält. Für andere dagegen ist die Stadt eine Stätte unendlicher innerer Einsamkeit. Manche Dichter sind intensiv am Stadtleben beteiligt und fühlen sich als Mitwisser all der Lichtund Schattenseiten einer großen Stadt. Andere Dichter dagegen schildern die Stadt von der Perspektive eines 
Beobachters und Außenseiters.

Jedoch ist die Darstellungsweise der Stadt nicht allein von den persönlichen Eindrücken und Empfindungen eines Dichters abhängig. Dichter sind 'Kinder ihrer Zeit', und in ihren Werken spiegelt sich--gewollt oder ungewollt--die Lebens- und Weltanschauung der jeweiligen Zeitepoche wider.

Vergleicht man die Stadtdichtung der Deutschen Demokratischen Republik mit der der Deutschen Bundesrepublik, so findet man verschiedene Weltanschauungen darin vertreten. Gedichte der DDR sind im Sinne des sozialen Realismus geschrieben und betonen fast ausschlieBlich nur die positiven Seiten: der Stadt, während in der Stadtlyrik der BRD vor allem die Probleme der modernen Großstadt dargestellt sind.

Die meisten Stadtgedichte der letzten hundert Jahre zeigen einen pessimistischen Ton und lassen durchklingen, daß die vielen Probleme einer Großstadt fast unlösbar erscheinen.

Laut statistischen Voraussagen werden im Jahre 2000 etwa 3,75 Milliarden Menschen in Städten leben. Man möchte wünschen, daß Goethe recht hat. Er sagte einmal in seinen Gesprächen mit Eckermann, daß große Städte Lebenselemente in sich tragen, von denen so mannigfache gute wirkungen ausgehen könnten: 3

Erst die Stadtlyrik der Zukunft wird darüber aussagen können. 


\section{ANMERKUNGEN}

KapiteI I

1 Georg Von Below, Das ältere deutsche Städtewesen und Bürgertum (Eielefeld und Leipzig Verlag Velhagen \& KIasing, 1898), S.135.

2 Ebda. S.37.

3 Ebda. S.38.

4 Ebda. S.78.

5 Gisela Iuther. Barocker Expressionismus? (The Hague: Mouton \& Co.. 1969), S.65.

6 Johannes Janssen, Die Geschichte des deutschen Volkes. Bd.I, Culturzustände (Freiburg/Breisgau: Herdersche Verlagsbuchhandlung, 1890), S.4II.

7 Ebda. Bd.I, S.403.

8 Ebda. Bd.2, S.205.

9 Ebda. Bd.2, 5.424.

10 Ebda. Bd.I, S. 516.

11 Below, S. 34 .

12 Janssen, Bd.6, S.30.

\section{Kapitel II}

1 Fritz Hofmann et al, $\mathrm{Hg}$. U. Uber die großen Städte. Gedichte (Berlin und Weimar: Aufbau Verlag, 1968), S.475:

2 Jakob van Hoddis (Pseudonym für Hans Davidsohn) und Ernst Iichtenstein übersetzten mehrere der französischen Gedichte.

3 Wolfgang Taraba, $\mathrm{Hg} \cdot$; Arno Holz. Phantasus (New York: Johnson Reprint Corp., I968J, S.Xi. 
4 Heinz Rölleke, Die Stadt bei Stadler, Heym und Trakl (Berlin, Erich Schmidt Verlag, 1966), S. 25.

5 Jethro Bithell, Moderm German Iiterature 18801950 (London: Methuen \& Co.. 1959), S.417.

6 Karl Ludwig Schneider, Zerbrochene Formen. Wort und Bild im Expressionismus (Darmstadt. Wissenschaftiche Buch geselischaft, 1967), S.53.

7 Silvio Vietta, Iyrik des Expressionismus (Tübingen: Deutscher Taschenbuchverlag, 1976), S.53.

8 Kurt Hiller; 1885-1972, wird manchmal als der Begründer, dann aber auch als Mitbegründer des Neuen clubs bezeichnet.

9 Albert Sörgel und Curt Hohoff, Dichtung und Dichter der Zeit (Düsseldorf: August Bagel Verlag, 1963), S. 152 .

10 Hofmann, s.482.

11 Ebda: 5.324 .

12 Ebda. S.486.

Kapitel III

1 Armin T.Wegner brachte mehrere stadtgedichtSammlungen heraus:

1909 Zwischen zwej Städten

1913 Das Antiitz der Städte

1924 Die straße mit den tausend Zielen

2 sörgel, Bd.2, 5.209

3 Bithell, S.I68.

4 Karl Krolow, Gesammelte Gedichte (Frankfurt/Miain: Suhrkamp Verlag, 1965), S.279.

5 Friedrich G. Kürbisch, Hg. Anklage und Botschaft. Die lyrische Aussage der Arbeiter (Hannover, Verlag J.H.W. Dietz, 1969), S.272.

6 Hans Dollinger, Hg., Außerdem (München, Scherz Verlag, 1967), S.420. 
7 DDR: $108,173 \cdot \mathrm{km}^{2}$ Fläche. 17 Mill.Einwohner. 158 Einwohner per $\mathrm{km}^{2}$.

BRD: $250,000 \mathrm{~km}^{2}$ Fläche. 62 Mill. Einwohner. 247 Einwohner per $\mathrm{km}^{2}$.

8 Ullrich Schmidt, Neue deutsche Iiteratur, Bd.17, Heft 8 (Berlin: Aufbau Verlag; 1969), S.64.

9 Ebda. S.116.

10 Ebda. $\$ .64$.

11 Karl Czok, Die Stadt (Leipzig: Urania Verlag, 1969), S.36.

12 Ebda. S.102.

13 Hans Stein, Hg., Detlev von Iiliencron. Ausgewählte Werke (Hamburg: HoIsten verlag, 1964), S. I52.

14 Wilhelm Duwe, Deutsche Dichtung des Zwanzigsten Jahrhunderts, Bd.I (Zürich: Orell FüssIi Verlag, 1969), S.46.

I5 Karl Ludwig Schneider, Der bildhafte Ausdruck in den Dichtungen Georg Heyms, Georg Trakls und Ernst Stadlers (Heidelberg, I96I), S.107.

16 Georg Trakl, Die Dichtungen (Salzburg: Otto Müller Verlag, 1938), S.59?

17 Hofmann, S.86.

18 Ebda. S.242.

19 Erich Kästner, Iyrische Hauspostille (Zürich: Atrium Verlag, 1961), S.156.

20 Bertolt Brecht. Gedichte, Bd.3 (Frankfurt/Main. Suhrkamp Verlag, 1961 ), S.155.'

21 Below, S.26.

22 sörgel, s.342.

23 Walter Muschg, Von Trakl zu Brecht. Dichter des

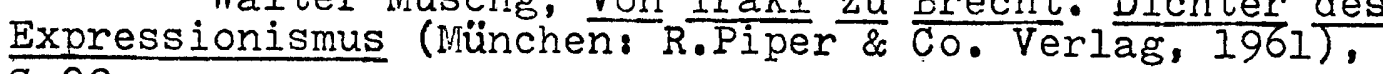
S.29。 
24 Hofmann, s.77.

25 Rudolf otto Wiemer, Hg. Bundes deutsch (Wuppertal: Peter Hammer Verla.g, 1974), S.86.

26 Ebda. S.93.

27 Ebda. 5.44.

28 Joachim Ret et al, Hg. . Manuskripte, Almanach neuer Prosa und Lyrik (Halle/Sale: Mitteldeutscher Verlag, 1969), S.299.

29 Johann Wolfgang von Goethe, Hermann und Dorothea, Teil III, Zeile 23 (New York, Nomilitan Co., 1899), S.32.

30 Michael. Hamburger, Hg., German Poetry 1910-1975 (New York: Urizon Books, 1976), s.92.

31 Ebda. S.90.

32 Karl Ludwig Schneider, Hg., Ernst Stadler, Dichtungen II, (HeideIkerg . 1954), న.179.

33 Karl Ludwig Schneider, Hg., Georg Heym, Dichtungen I (Heidelberg: 1964), S.379.

34 Fritz Hüser et al, Hg., Erlebtes Land--Unser Revier (Duisburg, Mercator Verlag, 1966), S.46.

35 Rainer Maria Rilke, "Worpswede«, Rilke Werke (Rilke Archiv, 1948), S.229.

36 Bertolt Brecht, Gedichte, Bd.6 (Frankfurt/Main: Suhrkamp Verlag, 1965), s.85.

37 Hugo Ernst Käufer, Hg., Revier Heute (Recklinghausen. Georg Bitter Verlag, 1972), 5.27.

38 Dimension. Contemporary German Arts and Letters Vol.IV (Austin: The University of Texas, 197i), S.378.

39 Josef Speck, Hg. , Kristalle. Moderne deutsche Gedichte für die Schule (runchen: KớseI Verlag AG, 196?), S.61.

40 Tintenfisch 5; Jahrbuch für Iiteratur (Berlin. Verlag Klaus Wagenbach), S.105.

41 Hofmann, S.29. 
42 Hofmann, s.376.

43 Ebda. S. 96.

44 The Oxford Book of German Verse,Ed.E.I.

Stahl (oxfordi Clarendon Press, 1927), S.57I.

45 Dimension. Vol.V, Heft 2, S.264.

46 Percey B. Shelley, Peter Bell The Third (1819), Part III.

47 Gotthold Ephraim Lessing, Minna von Barnhelm (Leipzig, Reclam Verlag, 1900), S.Il7.

48 Walther Killy et al, $\mathrm{Hg} .$, Die deutsche Iiteratur. Zwanzigstes Jahrhundert 1880-1933 Bd.? (Múnchen, C.H. Beck'sche Verlagsbuchhandlung, 1967), S.192.

49 Wilhelm Miuseler et al, $\mathrm{Hg}$. Wandlungen in der deutschen Dichtung (Göttingen: Musterschmidt Verlag, 1956), S.202.

$50 \mathrm{~W}_{i}$ Ihelm Emrich und Anita Holz, Hg. , Arno Holz

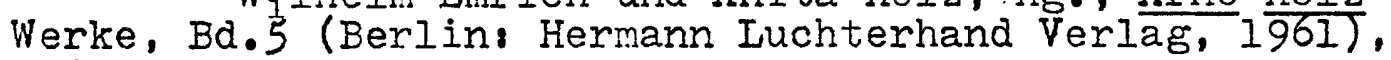
S.81.

51 Karl Ludwig Schneider, Zerbrochene Formen. Wort und Bild im Expressionismus (Darmstadt, Wissenschaftiiche Budgeselischaft, 1967), S.I23.

52 Hofmann, s.48.

53 Ebda. S.89.

54 Ebda. S.17.

55 Hüser, s.12.

56 Tintenfisch 5, S.105:

57 Kürbisch, S.273.

58 Johann Wolfgang von Goethe, Gespräche mit

Eckermann (Berlin: Aufbau Verlag, 1955), S.497.

59 Emrich, Bd.5. S.82.

60 Hofmann, s.20.

$6 I$ Rilke, Das Stundenbuch, S. 90. 
62 Kästner, Lyrische Hauspostille, S.156.

63 Hofmanr, s.279.

64 Alexander Abusch, Literatur im Zeitalter des Sozialismus (Berlin: Aufbau Verlag, 1967), S.332.

65 Hofmann, s.96.

66 Jean Jaques Rousseau, Émile, 1762.

67 Friedrich Nietzsche, Also sprach Zarathustra, Teil III, "Vom Vorübergehene (Stuttgart: Alfred Kröner Verlag, 1930), S.194.

68 Friedrich Bohne, Hg., Wilhelm Busch Werke, Bd.2, "Die fromme. Helener (Wiesbaden! Emil Vo $\overline{l l m e r}$ Verlag, 1968), S.204.

69 steir, s.152.

70 Emrich, Bd.5, S.105.

71 Karl Otten, Expressionismus-grotesk (Zürich Peter Schifferli AG, 1962), S.72.

72 Jörg Ulrich Fechner, Das deutsche Sonett (München: W.Finck Verlag, 1969), S.242.

73 Hermann Friedmann und Otto Mann, Expressionismus. Gestalten einer literarischen Bewegung (Heidelberg. Wolfgang Rothe verlag, 1956), S.77.

74 Hofmann, S.111.

75 Erich Kästner, Gedichte(Köln: Verlag Kiepenheuer \& Witsch, 1959), s.192.

76 Hofmann, s.268.

77 Ebda. s. 382 .

78 Text und Kritik,Zeitschrift für Literatur, Heft 9 (stuttgart-München-Hannover: Richard Boorberg Verlag), S.26. 
KapiteI IV

1 Franz Grillparzer Werke, Hg.Franz Rowas (München, Carl Hanser Verlag, 1950), S.131. S.32.

2 Rölleke, Die Stadt bei Stadler, Heym und Trakl,

3 . sörgel, Bd.2, S. 543.

4 Fritz liartini et al, $\mathrm{Hg}$., Klassische deutsche Dichtung. Iyrik, Bd.18 (Feiburg: Verlag Herder, 1969), S.564.

5 Ebda. 5.574 .

6 Hofmann, s.77.

7 Rölleke, S.38.

8 Silvio Vietta, Lyrik des Expressionismus (Tübingen. Deutscher Taschenbuchverlag, $\overline{1976), ~ S .46 . ~}$

9 Martini, Bd.18, S.642.

10 Kürbisch, S.271.

II Rudolf Ibel, Hg., Jahrbuch zeitgenössischer Iyrik (Hamburg 1958/59).

12 Hofmann, S.313.

13 Georg Trakl Die Dichtungen. Bd.I (Salzburg: Otto

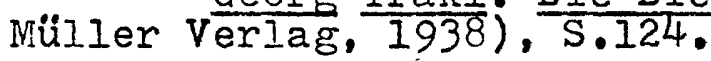

14 Hofmann, S.35.

15 Dieter Wèllershoff, Hg., Gottfried Benn. Gedichte. Bd. 3 (Wiesbaden: Limes Verlag, 1960), S.16.

16 Hofmann, S.93.

17 Müseler, S.202.

18 Rilke, Das Stundenbuch, S.90。

19 Kästner, Gedichte, Ed. I,S.92.

20 Käufer, S.26. 
Kapitel V

$1 \mathrm{Killy}, \mathrm{Bd} .7, \mathrm{~s} .91$.

2 Ebda. S.9I.

3 Müseler, S.250.

4 Emrich, S.251.

5 Hofmann, S.478.

6 Ebda. S.477.

7 Ebda. 5.7.

8 Ebda. 5.43.

9 Ebda. S. 50.

10 Ebda. S.174.

11 Ebda. 5.441 .

12 Neue deutsche Hefte, Hg. Joachim Günther, Vol.18, Heft 4 (Berlini 1971), S.52。

13 Dimension. Heft 2, $1972, \mathrm{~S} .310$.

Kapitel VI

1 Hermann Vaschek, Hg., Deutsche Chroniken, Reihe 4 , Bd.5 (Darmstadt: Wissenschaftliche Buchgeselischaft, 1936), S.91.

2 Ebda. Reihe 13a, Bd.2, S.186.

3 Peter Hamm, Hg., Aussichten. Junge Lyriker des deutschen Sprachraums (vünchen Biederstein Verlag, 1966), S.325.

4 Helmut Preissler, $\mathrm{Hg} .$, Du, unsere Liebe. Gedichte (Berlin: Deutscher Militärveriag, 1969), S.34.

5 Neue deutsche Iiteratur, Heft 8, 1970, s.116.

6 Hofmann, s.579. 


\section{Martini, Bd.18, s.712. \\ 8 Ebda. S.713.}

Kapitel VII

I sörgel, Ed.2, S.755.

2 Ebda. S.755.

3 Hofmann, S.182.

4 Kästner, Gedichte, Bd.I, S.40.

5 Kästner, Lyrische Hauspostille, S.35.

6 Christian Morgenstern, Gesammelte Werke, (München: R.Piper \& Co. Verlag, 1965), S. 319.

7 Akzente, Heft 2/1970, S.122.

Kapitel VIII

1 Friedrich Hölderlin, Sämtliche Werke (Stuttgart: W.KohIhammer Verlag, 1953), S.I4.

2 Rolf Hochhuth, Hg., Theodor Storm. Gesammelte Werke (Güterlsloh: Bertelsmann Verlag, 1962), S.5.

3 sörgel, Ba.2, s.630.

4 Hofmann, S. 40.

5 Ebda. 5.12.

6 Ebda. S.36.

7 German Life and Letters. A quarterly Review, Ed. L.A.Willoughby et al, 1950751 (0xford), S.296.

8 Wolfgang Borchert. Das Gesamtwerk (Hamburg: Rowohlt Verlag, 1974$),$ S.20.

9 Preissler, S.108.

10 Ebda. 5.326. 


\section{Kapitel IX}

1 Kurt Mautz, Mythologie und Gesellschaft im Expressionismus (Frankfurt: Athenăum Verlag, 196I), S.6I.

2 Egbert Krispyn, Georg Heym. A reluctant Rebel (Gainesville: University of Florida Press, 1968), S.88.

3 Ebda. $\mathbf{5 . 8 8 .}$

4 sörgel, S.187.

5 Akzente, Heft 6, 1956/57, S.481

6 sörge1, s.334.

7 Ebda. S.34I.

8 Hofmann, S.215.

Kapitel $X$

1 Rölleke, S.108.

2 Hofmann, S.9.

3 Ebda. S.39.

4 Schneider, Ernst Stadler, Dichtungen I, S.137.

5 Ebda. S.137.

6 Hofmann, S.I89.

7 Ebda. $\mathrm{S} .343$.

8 Ebda. S.106.

9 Rölleke, S.108.

10 Hofmann, 5.42 .

11 Hüser, S.50.

12 Wolfgang Borchert. Werk, S.19.

13 Hofmann, s.379.

14 Mautz, S.360. 
KapiteI XI

1 Czok, S.102.

2 Bertolt Brecht, Gedichte, Bd.I (Frankfurt/Main: Suhrkamp Verlag, 1965), S.73.

3 Goethes Gespräche mit Eckermann, Brief vom 23. Oktober 1828 (Berlin: Aufbau Verlag, 1955), $\mathrm{s} .436$. 
Abusch, Alexander. Iiteratur im Zeitalter des Sozialismus. BerIin: Aufbau-Verlag, 1967.

Akzente, Zeitschrift für Dichtung. München, Karl Hanser Verlag.

Arno Holz. Phantasus.Ed.Wolfgang Taraba. New York: Johnson Reprint Corp., 1968.

Below, Georg v. Das ältere deutsche Städtewesen und Bürgertum. Bielefeld und Leipzig, Verlag Verhagen \& Klasing, 1898.

Benn, Gottfried. Gedichte. Wiesbaden: Iimes Verlag, 1960.

Bertolt Brecht. Gedichte. Frankfüt/Mains Suhrkamp Verlag, 1961.

Bithell. Jethro. Modern German Literature 1880-1950. London: Methuen \& Co., 1959.

Bohne, Friedrich, Hg. WiIhelm Busch. Gesammelte Werke. Wiesbaden, Emil Vollmer Verlag, 1968.

Czok, Karl. Die Stadt. Leipzig: Urania Verlag, 1969.

Deutsche Geschichte.Hg.Hans Joachim Bartmuss et al. BerIin: $\sqrt{E B}$ Deutscher Verlag der Wissenschaft, 1967.

Dimension. Contemporary German Arts and Letters. Austin: The University of Texas.

Dollinger, Hans, Hg. Außerdem. München, Scherz Verlag, 1967.

Duwe, Wilhelm. Deutsche Dichtung des zwanzigsten Jahrhunderts. Zürich: Orell Füssii Verlag, 1969.

Emrich, Wilhelm und Anita Holz, Hg. Arno Holz Werke. Berlin: Hermann Luchterhand Verlag, 1961.

Fechner, Jörg Ulrich. Das deutsche Sonett. München: W. Fink Verlag, 1969 . 
Friedmann, Hermann und Otto Nann, Hg. Expressionismus. Gestalten einer literarischen Bewegung. Heidelberg: WoIfgang Rothe Verlag, 1956.

Georg Trakl. Die Dichtungen. Salzburg, Otto Müller Verlag, 1938 .

German Iife and Letters. A quarterly Review. Ed. I.A. Willoughby et al. oxford Easil Blackwell.

Goethe, Johann Wolfgang v. Gespräche mit Eckermann. Berlin: Aufbau-Verlag, 1955.

Hamburger, Michael, Ed. East German Poetry. New York: E.P. Dutton \& Co., 1973.

York Urizon Books, 1976.

German Poetry 1910-1975. New

Hamm, Peter, Hg. Aussichten. Junge Lyriker des deutschen Sprachraums. München: Biederstein Verlag, 1966.

Hermlin, Stephan. Gedichte und Prosa. Berlin. Verlag Klaus Wagenbach, 1969.

Hochhuth, Rolf, Hg。 Theodor Storm. Gesammelte Werke. Gütersloh: Bertelsmann Verlag, 1962.

Hölderlin, Friedrich. Sämtliche Werke. Stuttgart:

W. KohIhammer Veriag, 1953.

Hofmann, Fritz et al, Hg. Uber die großen Städte. Gedichte. Berlin und Weimar: Aufbau Verlag, 1968.

Holborn, Hajo. A History of Modern Germany. 3 Vols. New York: Alfred A. Knopf, 1969.

Hüser, Fritz et al, Hg. Erlebtes Land--Unser Revier. Duisburg, Mercator Verlag, 1966.

Jahrbuch zeitgenössischer Lyrik. Hg. Rudolf Ibel. Hamburg.

Janssen, Johannes. Die Geschichte des deutschen Volkes.

6 Bd. Freiburg: Herder'sche Verlagsbuchhandlung, 1890.

Kästner, Erich. Gedichte. Köln: Verlag Kiepenhauer \& Witsch, 1959. Verlag, 1960 . 
Käufer, Hugo Ernst, Hg. Revier Heute. Recklingshausen: Georg Bitter Verlag, 1972 .

Killy, Walther et al. Die deutsche Iiteratur. Zwanzigstes Jahrhundert. 1880-1933. München: C.H.Beck'sche Verlagsbuchhandlung, I967.

Krispyn, Egbert. Georg Heym. A reluctant Rebel. Gainesville, University of Florida Press, 1968.

Krolow, Karl. Gesammelte Werke. Frankfurt/Main. Suhrkamp Verlag, 1965.

Kürbisch, Friedrich G.,Hg. Anklage und Botschaft. Die Iyrische Aussage der Arbeiter. Hannover: VerIag J.H.W. Dietz, 1969.

Iaschen, Gregor. Lyrik in der DDR. Frankfurt/Main. Athenäum Verlag, 197 i.

Lessing, Gotthold Ephraim. Minna von Barnhelm. Leipzig: Reclam Verlag, 1900.

Lexikon der Goethe Zitate. Richard Dobel, Hg. Zürich und Stuttgart Artemis Verlag, 1968.

Iuther, Gisela. Barocker Expressionismus? The Hague: Mouton \& Co... 1969.

Lyrik des expressionistischen Jahrzehntes. Wiesbaden: Limes Verlag, 1955.

Vartini, Fritz et al. Hg. Klassische deutsche Dichtung. Lyrik. Feiburg: Verlag Herder, 1969.

Maschek, Hermann, Hg. Deutsche Chroniken. Darmstadt, Wissenschaftliche Euchgesellschaft, 1936.

Nautz, Kurt. Mythologie und Geselischaft im Expressionismus. Die Dichtung Georg Heyms. Frankfurt/Main: Athenăum Verlag, 1961. .

Morgenstern, Christian. Gesammelte Werke. München R.Piper \& Co. Verlag, 1965.

Miüseler, Wilhelm et al. Wandlungen in der deutschen Dichtung. Göttingens Musterschmidt verlag, 1956.

Muschg, Walter. Von Trakl zu Erecht. Dichter des Expressionismus. München: R.Piper \& Co. Verlag, I961. 
Neue deutsche Hefte. Joachim Günther, Hg. Berlin.

Neue deutsche Literatur. Deutscher Schriftstellerverband, $\mathrm{Hg}$. Berlin: Aufbau Verlag.

Nietzsche Friedrich. Also sprach Zarathustra. Stuttgart: Alfred Kröner Verlag, 1930.

Otten Karl. Expressionismus-grotesk. Zürich, Peter Schifferli AG, 1962 .

Preissler, Helmut, $\mathrm{Hg}$. Du, unsere Liebe. Gedichte. Berlin, Deutscher Militärverlag, 1969.

Ret, Joachim et al, Hg. Manuskripe. Almanach neuer Prosa und Lyrik. Halle/saale: Mizteldeutscher Verlag, 1969.

Rilke, Rainer Maria.. Das Stundenbuch. Frankfurt/Main: Insel Verlag, 1955.

Rilke, Rainer Maria. "Worpsweder. Rilke Werke. Rilke. Archiv, 1948.

Rölleke, Heinz. Die Stadt bei Stadler, Heym und Trakl. Berlin: Erich Schmidt Verlag, 1966.

Rousseau, Jean Jaques. Émile. Transl.Barbara Foxley. New York, E.P. Dutton, 1911.

Rowas, Franz, $\mathrm{Hg}$. Franz Grillparzer. Werke. München. Carl Hanser Verlag, 1950.

Schneider, Karl Ludwig, Hg. Ernst Stadler. Dichtunger. Hamburg, Verlag Heinrich Ellermann, 1954.

, Hg. Der bildhafte Ausdruck in den Dichtungen Georg Heyms, Georg Trakls und Ernst Stadlers. Heidelberg. 1961 . , Hg. Georg Heym: Dichtungen. Hamburg, Verlag Heinrich Ellermann, 1964.

- Zerbrochene Formen. Wort und Bild im Expressionismus. Darmstadt, Wissenschaftliche Budgesellschaft, 1967.

Sörgel, Albert et al. Dichtung und Dichter der Zeit. Düsseldorf: August Bagel Verlag, 1963. 
Speck, Josef, Hg. Kristalle. Moderne deutsche Gedichte für die Schule. München, Kösel Verlag AG, 1967.

Stein, Hans, Hg. Detlev von Iiliencron. Ausgewählte Werke. Hamburg: Holsten Verlag, 1964.

Taraba, Wolfgang, Hg. Arno Holz. Phantasus. New York: Johnson Reprint Corp., 1968.

Text und Kritik. Zeitschrift für Iiteratur.StuttgartMünchen-Hannover, Richard Boorberg Verlag.

The Oxford Book of German Verse.Ed. E.I. Stahl. Oxford. Clarendon Press, 1927 .

Tintenfisch, Jahrbuch für Iiteratur. Berlin, Verlag Klaus Wagenbach.

Vietta,Silvio. Iyrik des Expressionismus. Tübingen. Deutscher Taschenbuchverlag, 1976.

Wiemer, Rudolf Otto, Hg. Bundes deutsch. Wuppertal, Peter Hammer Verlag, 1974 .

Wiese, Benno v.,Hg. Die deutsche Lyrik. Düsseldorf: August Bagel verlag, 1957.

Wirkendes Wort. Düsseldorf: Pädagogischer Verlag Schwann.

Wolfgang Borchert. Das Gesamtwerk. Hamburg: Rowohlt Verlag, $1974_{0}$. 
VERZEICHNIS

DER DICHTER UND GEDICHTE

\begin{tabular}{|c|c|c|}
\hline Adametz, Wilhelm & Großstadtkavalkade & 47 \\
\hline Arlt, Freimut & Hauptstadt der DDR & 71 \\
\hline Arlt, Peter & Der Rote Turm in Halle & 24 \\
\hline Bartsch, Kurt & Berlin & 57 \\
\hline Becher, Johannes & $\begin{array}{l}\text { Städte } \\
\text { Stein } \\
\text { Die Huren } \\
\text { Fliegerbomben prasselten } \\
\text { De Profundis }\end{array}$ & \\
\hline Benn, Gottfried & Saal der kreißenden Frauen & \\
\hline Bisinger, Gerald & Ballade-Ode Berlin-Berlin & \\
\hline Boldt, Paul & $\begin{array}{l}\text { Stadt III } \\
\text { Berlin }\end{array}$ & \\
\hline Borchert, Wolfgang & $\begin{array}{l}\text { In Hamburg } \\
\text { Großstadt } \\
\text { Graurotgrünes Großstadtlied }\end{array}$ & \\
\hline Brecht, Bertolt & $\begin{array}{l}\text { Die ärmeren Mitschüler aus } \\
\text { den Vorstädten } \\
\text { Städtische Landschaft } \\
\text { Rückkehr } \\
\text { Als unsere Städte in } \\
\quad \text { Schutt lagen } \\
\text { Unter ihnen sind Gossen }\end{array}$ & \\
\hline Brinkmann, Rolf $\mathrm{D}$ : & Programmschluß & 40,4 \\
\hline Bröger, Karl & Zweites Sonett & \\
\hline Busch, wilhelm & Als Ienchen in die Stadt kam & \\
\hline Dehmel, Richard & $\begin{array}{l}\text { Predigt ans Großstadtvolk } \\
\text { Ausschau bei Nacht }\end{array}$ & \\
\hline
\end{tabular}




$\begin{array}{llr}\text { Doutiné, Heike } & \text { Transparent } & 42 \\ \text { Engelke, Gerritt } & \text { Mietskaserne } & 32 \\ & \begin{array}{l}\text { Ich will hinaus } \\ \text { Heimkehr }\end{array} & 41 \\ \text { Franz, Michael } & \text { Erster Mai 1946 } & 74 \\ \text { Fürnberg, Louis } & \text { Abend } & 91 \\ \text { George, Stefan } & \text { München } & 81 \\ \text { Goethe, Johann W." } & \text { Krumme Gäßchen } \\ \text { Gryphius, Andreas } & \text { Untergañ der Stadt Freystadt } & 26 \\ \text { Hallards, , Ruth } & \text { Threnen des Vatterlandes } \\ \text { Hart, Julius } & \text { Kirche } & 23 \\ & \text { Die Fahrt nach Eerlin } & 67\end{array}$

Hermlin, Stephan Ballade von der Uberwindung der Einsamkeit

Heym, Georg

Die Vorstadt

Die Schatten I

Die Dämonen der Städte

Heyse, Gerd

Stadtbild II

Hoddis, Jakob van Morgens

Hölderlin, Friedrich Heidelberg

Holz, Arno

Phantasus III

Großstadtmorgen

Wintergroßstadtmorgen $28,44,48$

54
68

Kästner, Erich

Vorstadtstraßen

Besuch vom Lande

Mädchens Klage

Chor der Fräulein

Sozusagen in der Fremde

Kahlau, Heinz

Allein

40

Morgenfurcht

62

KanehI, Oskar

Kanalbrücke Eerlin

Kaspar, Hans

Frankfurt 
Klabund

Klemm, Hermann

Körner, Wilhelm

Koch, Thilo

Krolow, Karl

Kunert, Günter

Irassang, Iwan

Lehner, Horst

Leifhelm, Hans

Leonard, Rudolf

Lichtenstein, Alfred.
Proleten

41,51

Tod in Eerlin

65

harmonisch

79

Die gegenwärtige Stadt

23

Entstehung einer stadt

22

Es sind die Städte

Wie mir heute meine

Stadt erschien

17

70

Die Automammuts

91

Zeit ein Gedicht $\mathrm{zu}$ machen 58

Industriesonntag

92

Von Stadt zu Stadt

70

Die Nacht

Sonntagnachmittag

Gesänge an Berlin

Die Zeichen

Liliencron, Detlev v.

Der schöne Glockenschlag In einer großen Stadt

27.54

Iinde, Ctto zur

Die Stadt

Stadt und Landschaft

Loerke, Oskar

Blauer Abend in Berlin.

92

Iotz, Wilhelm

Hart stoßen sich die Wände

69

Mehring, Walter

Die Linden lang

77

Morgenstern, Christian

Aus der Vorstadt

79

Nyland, Rose

Die Stadt

84

Preissler, Helmut

Neubauten

35

Rauner, Iiselotte

Lagebericht

34

Reinfrank, Arno

Mutation

39

Renner, Gustav

In der Großstadt 
Rilke, Rainer Maria

Sachs, Hans

Scharf, Ludwig

Schmidt, Ullrich

Schubert, Max Oswin

Schulze, Axel

Stadler, Ernst

Steinbach, Walter

Sternberg, Leo

Stiller, Klaus

Storm, Theodor

Stramm, August

Thomas, Ingelux

Trakl, Georg

Tucholsky, Kurt

Vehrings, Marleen

Wegner, Armin

Weinert, Erich

Wille', Bruno
Das ist dort

Denn, Herr, die großen

Städte

22

49,65

Sollt uns denn Gott nit grimmig plagen

Begegnis

61

Unterwegs

24

Dresden

74

Farben der Städte

93

Abendschluß

Dämmerung

Dämmerung in der Stadt

Gang in der Nacht

33.61

37

90

90

In mitternächtgen Städten

88

Du schöner Iärm des Lebens

46

Mieter als Vermieter

35

Die Stadt

80

Freudenhaus

56

Blinde Stadt

62

Vorstadt im Föhn

An die Verstummten

28

64

Lied von der GIeichgültigkeit

57

Wiegenlied.

Ringel Rangel Rose

39
66

Der Zug der Häuser

21

Gesang von den Straßen

der Stadt

82,90

Helles Iied aus dunklem

Republikanischer Abend

Straßen

49

Straße 